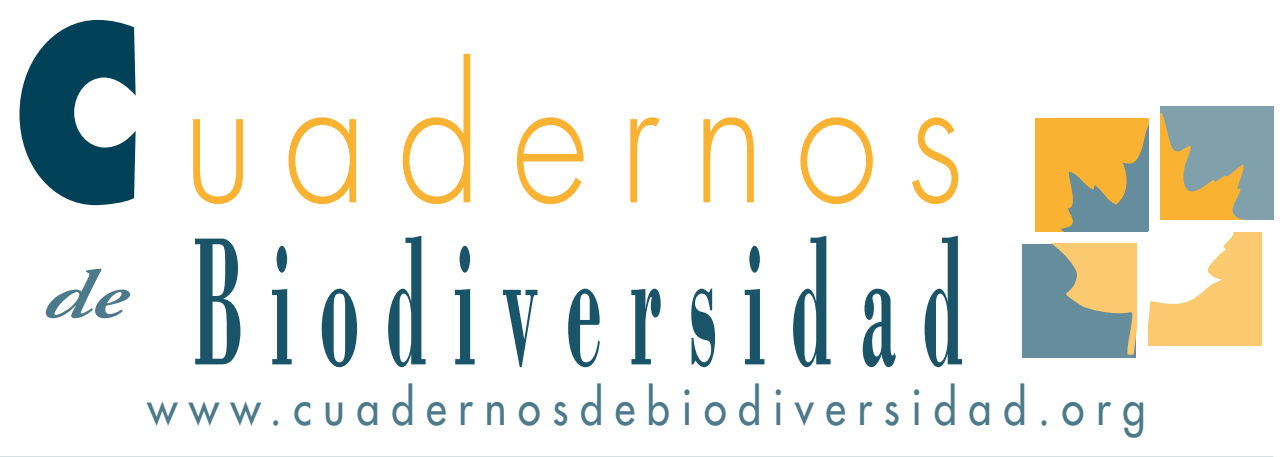

\title{
Entomología cultural y conservación de la biodiversidad. Los insectos en las Artes Mayores
}

\section{Blas ${ }^{1}$ \& J. Del Hoyo ${ }^{2}$}

i Departamento de Biología Animal, Facultad de Biología, Universidad de Barcelona, BarceLONA, EsPAÑA. MBLAS@UB.EDU

2 Departamento de Diseño e Imagen, Facultad de Bellas Artes, Universidad de Barcelona, Barcelona, España. Jesusdelhoyoarjona@ub.edu

\section{ABSTRACT}

The aim of this paper is to state the importance of insects in culture and, to be specific in the traditionally called "High Arts". Also, how cultural variety, trends in art, and obviously the idiosyncrasy of those artistic objects where insects are used as a source of inspiration, obviously have an impact on the different forms in which insects are represented.

We will show a selection of examples as a chronological, not comprehensive guide through the manifold forms and symbolism linked to the representation of insects within each of these Arts.

Thus, we demonstrate how insects are closely and profusely connected to all cultural manifestations.
Also, how their long-standing relationship with mankind and its cultural milieu, even in spite of occasionally having negative connotations has in fact helped towards the preservation of biodiversity. There is no denying that cultural diversity and biodiversity are closely related.

\section{KEY WORDS:}

Cultural Entomology, high arts, representation, conservation. 


\section{INTRODUCCIÓN}

Los insectos constituyen una parte muy importante de la biodiversidad, aunque no siempre se les ha dado la importancia que merecen. Constituyen el grupo más numeroso del reino animal, habiéndose descrito más de un millón de especies, aunque este número varía según las fuentes consultadas. Además, este elevado número de especies presentan una gran diversidad morfológica que afecta a sus formas, colores, tamaños y formas de vida.

La conservación de los insectos es muy importante para el mantenimiento de los ecosistemas, ya que muchas especies son beneficiosas participando en procesos tan importantes como la polinización, el control de plagas y malas hierbas o la degradación de la matería orgánica entre otros. Son fuente de alimento de otros organismos, tanto invertebrados como vertebrados, incluido el hombre y también nos proporcionan sustancias, como la miel, la seda, la cera, etc.., que han sido y son muy valoradas por la humanidad. Del millón de especies conocidas, únicamente unas 3000 son perjudiciales por transmitir patógenos, causar plagas o bien por transmitir o causar enfermedades al hombre o a los animales. Todos los insectos, incluidos los que pueden ser considerados como indiferentes, juegan un papel muy importante en el equilibrio de los ecosistemas y por ello deben ser conservados.

El potencial uso de los insectos representa una contribución importante para el debate de la biodiversidad, como perspectiva para la valoración económica y cultural de animales considerados habitualmente como inútiles. Hoy en día no se puede hablar de biodiversidad sin tener en cuenta la diversidad cultural. La biodiversidad no solo es fruto de la naturaleza, si no que en muchos casos depende de la acción del ser humano, sobre todo en sociedades no industriales (Costa-Neto, 2012).

Los insectos están en la naturaleza desde hace 350 millones de años y su influencia en la humanidad ha sido y es muy importante. Son fuente de inspiración de obras de arte, de piezas musicales, de obras literarias, de elementos decorativos, de las artes plásticas, de la moda y complementos y un largo etc... (Calle, 2009). Esta implicación de los insectos en la cultura ha sido reconocida en un área de investigación denominada "Entomología Cultural", que se puede definir como la influencia de los insectos en la historia de la humanidad (Hogue, 1987). De hecho, los insectos están profundamente insertados en la vida del ser humano, en aspectos cognitivos, afectivos y de comportamiento (Costa-Neto, 2002). La inclusión de los insectos en algunas culturas es tan importante que han sido asociados a divinidades e incluso en algunas culturas, existe la creencia de que los hombres se han originado a partir de los mismos insectos (Hogue, 1987).

No se puede hablar de biodiversidad sin considerar la diversidad de cultural (Sachs, 1997). Para mantener la biodiversidad se deben preservar y mantener las culturas que han interactuado con los insectos, sus hábitos y biologías, pues es la forma de asegurar la conservación de estas especies.

En las culturas primitivas, la relación con el medio natural es mayor que en las culturas industrializadas. Del mismo modo, también había más conocimiento cultural sobre la relación insecto-hombre en culturas antiguas que en las modernas. Pero en todos los casos hay manifestaciones artísticas en las que los insectos han sido y son fuente de inspiración. Este hecho ha podido influir en la valoración positiva de algunos grupos de insectos lo que sin duda ha podido favorecer su conservación.

\section{LOS INSECTOS EN LAS ARTES MAYORES}

Los insectos están presentes tanto en las Artes Mayores, como en las Artes Aplicadas o Artes Menores. En este artículo nos centraremos en cómo han sido utilizados los insectos en las Artes Mayores, que según la perspectiva clásica se clasifican en: espaciales o visuales-Arquitectura, Escultura y Pintura-; temporales o fonéticas-Música y Declamación (literatura, poesía y "teatro")-, aunque en este artículo hemos vinculado Teatro y Música como una unidad, de acuerdo con las consideraciones más actuales; y audiovisuales o mixtas-Danza y el "Cine"- éste último evidentemente como aportación actual, no Clásica - debida a Ricciotto Canudo (1877- 
1923) que la propuso como séptima arte en 1911 (http://es.wikipedia.org/wiki/Bellas_artes; http:// en.wikipedia.org/wiki/Ricciotto_Canudo).

En este artículo intentaremos dar una idea del uso de los insectos en las siete artes mayores, que son el sentido morfológico, filosófico, metafórico, simbólico, plástico directo o indirecto, de forma superficial o estructural, anecdótica o profunda entre otros. No se trata de un trabajo exhaustivo sino de poner de manifiesto mediante algunos ejemplos las distintas formas de representar los insectos y la evolución de su manifestación en cada una de las artes mayores, así como su significado, en la medida de lo posible.

\section{ARQUITECTURA}

Hay ejemplos de la arquitectura clásica que se inspiran en las construcciones de los insectos, se puede plantear en ese sentido la similitud entre las tumbas Micénicas (1550-1100 aC) y la formas de los panales silvestres de las abejas, pero no es hasta finales del XIX y principios del XX y sobre todo entre los arquitectos modernistas, cuando esa intuición se pudo considerar como certeza. Durante el modernismo es frecuente utilizar motivos de la naturaleza, tanto vegetales como animales en los edificios. Los insectos han sido escogidos especialmente para la decoración, ya sea la exterior, fachadas, forja de cerramientos, vidrieras de ventanas, de puertas y otros complementos como en diversos motivos presentes en su interior. Ejemplos relevantes son la Casa Fajol o Casa de la Mariposa y la Casa Manuel Llopis. La primera de 1912 es obra de Josep Graner i Prat (1844-1930), que corona su fachada con una enorme mariposa, hecha de trozos de cerámica, técnica tradicional catalana denominada trencadis. La segunda, de 1903, es obra de Antoni Gallissà i Soqué (1861-1903) y presenta unos esgrafiados que reproducen insectos que casi pasan desapercibidas en una observación rápida, su autor es Josep Maria Jujol (1879-1949) (Figs. 1a y b).

Antonio Gaudí (1852-1926), máximo exponente del modernismo utiliza de forma recurrente referencias al mundo animal en general y al de los
Figura 1 : Josep Maria Jujol i Gibert (Tarragona, 16 de septiembre de 1879- Barcelona, 1 de mayo de 1949), es el autor de los esgrafiados que decoran la fachada. Arquitecto, pintor, diseñador y mundialmente conocido como el más cercano e íntimo colaborador y discípulo de Antonio Gaudí (1852-1926).

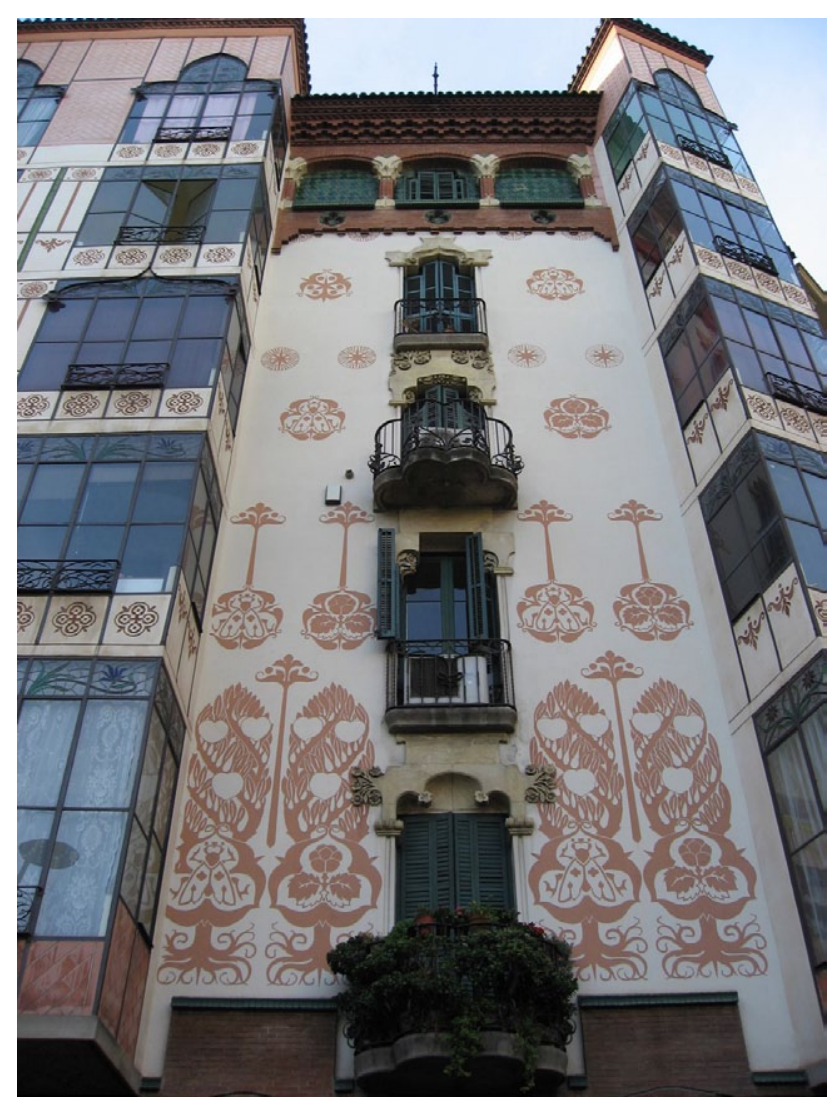

Figura 1 a: aspecto general del lateral derecho de la fachada.

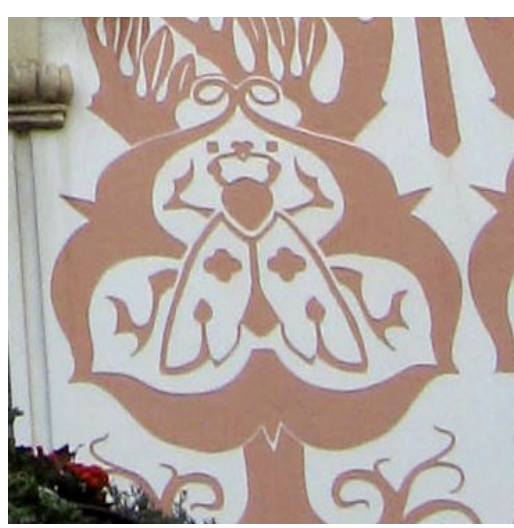

Figura 1 b: detalle de uno de los insectos esgrafiados. 
insectos en particular. Algunos estudiosos consideran que Gaudí se pudo inspirar en la estructura de los nidos de termitas para el diseño de las torres del templo expiatorio de la Sagrada Familia. Las estructuras hexagonales de los panales de las abejas están recogidas en sus diseños de baldosas que podemos ver mientras caminamos por en el Paseo de Gracia de Barcelona y en diversas celosías y cerámicas con función decorativa en algunas de los edificios por él diseñados.

Un edificio singular y muy especial es La casa de los paraguas, situada en las Ramblas de Barcelona. A finales del siglo XIX fue reformada por Josep Vilaseca en una época previa a la Exposición Universal de 1888. El estilo del edificio es precursor del modernismo y su particularidad reside en la coexistencia de elementos decorativos inspirados en culturas orientales (flores e insectos) con otros como abanicos y un gran dragón chino de hierro fundido (Figs. 2a y b)

En la arquitectura contemporánea se imponen

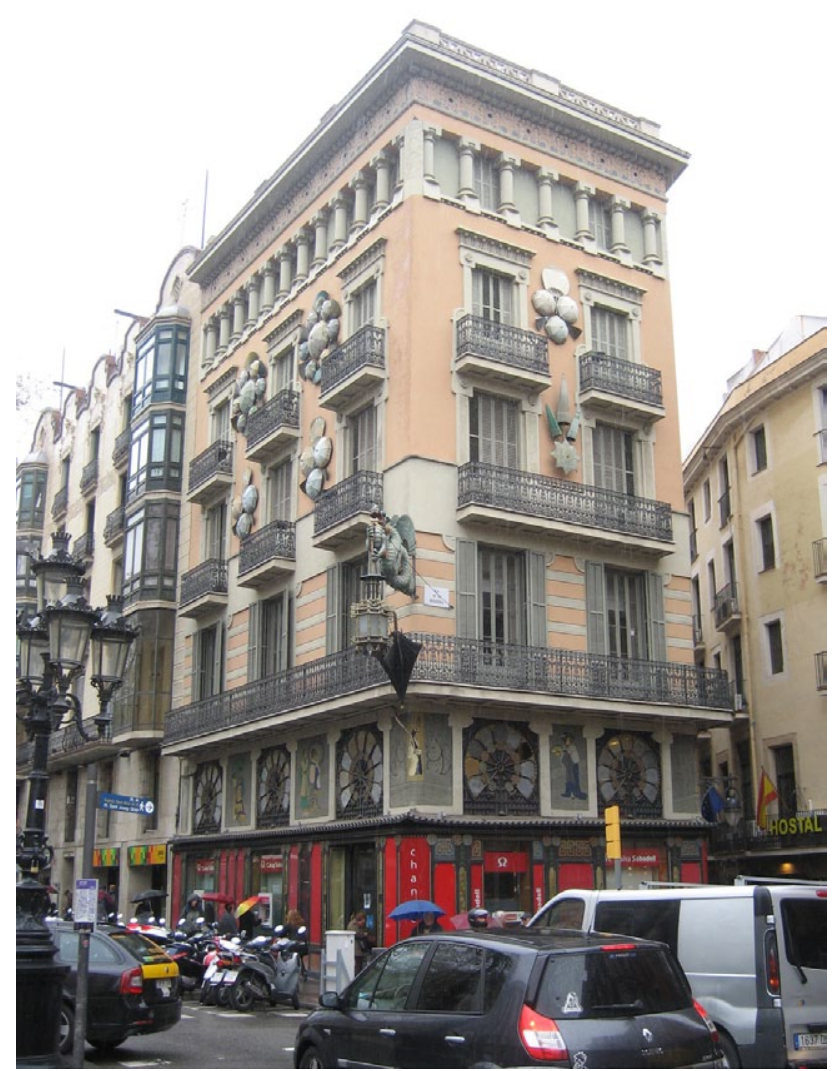

Figura 2 a: La denominada popularmente Casa de los paraguas, originalmente era la casa de Bruno Cuadros, reformada 1883, adquirió el aspecto actual en 1888 .

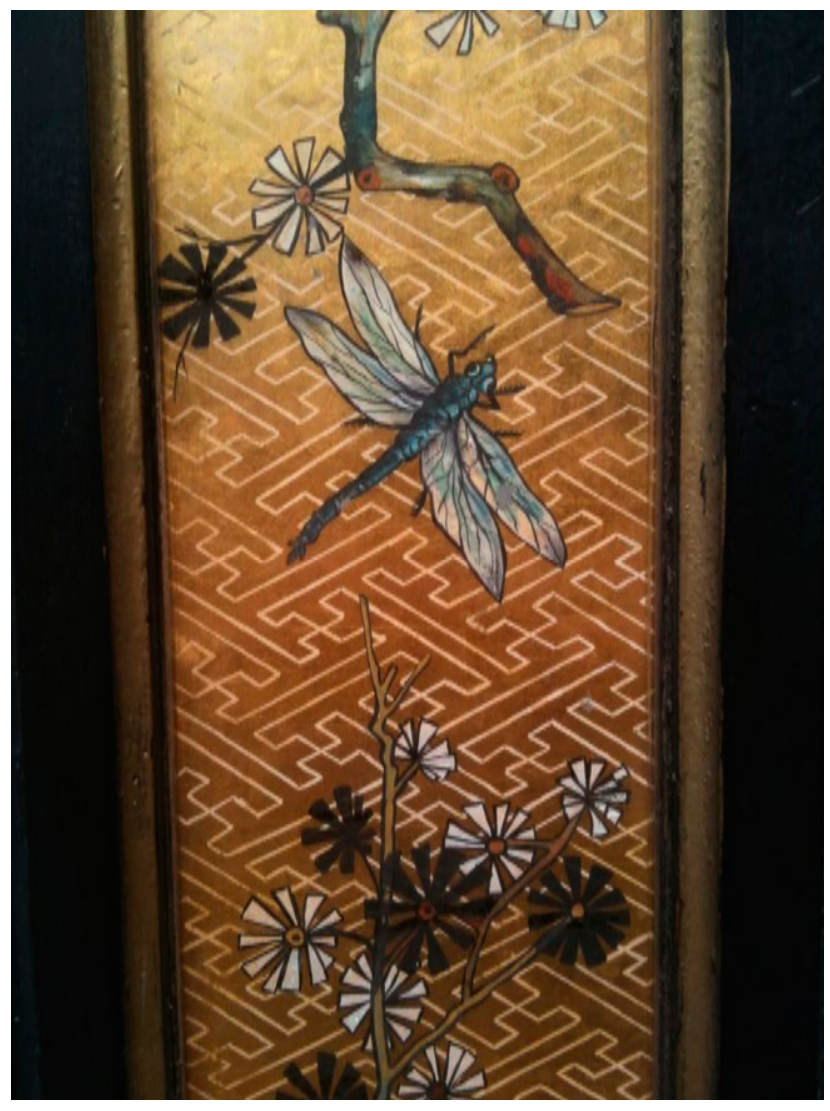

Figura 2 b: Detalle de una de los insectos, del orden odonatos, que aparecen reproducidos en los paneles exteriores que decoran, al estilo oriental, la fachada a la altura de la calle.

innovaciones arquitectónicas que pueden ser estéticas, permitiendo la integración de los edificios en el medio que los rodea, como es el caso del Jardín Botánico de Quindio (Colombia), que tiene forma de mariposa; de tipo estructural, permitiendo la reducción de gastos en el material de construcción, el menor peso de las estructuras o el mejor aprovechamiento de los espacios internos del inmueble, como es el caso del Harpa Concert Hall and Conference Center de Reykjavik (Islandia) obra del arquitecto Henning Larsen (1925-2013) (Figs. 3a y b). Este edificio tiene clara referencia a la estructura de las colmenas. Las innovaciones también pueden ser de tipo funcional, como el Centro Eastgate, en Hurare (Zimbabwe), obra del arquitecto Mick Pearce, que está provisto de refrigeración pasiva, similar a la que existe en los termiteros o bien para el aprovechamiento solar como ocurre en el Proyecto Eden en 
Cornwall (Gran Bretaña), edificio cuya la estructura recuerda a los ojos compuestos de los insectos. (Llorens Duran, 2008).

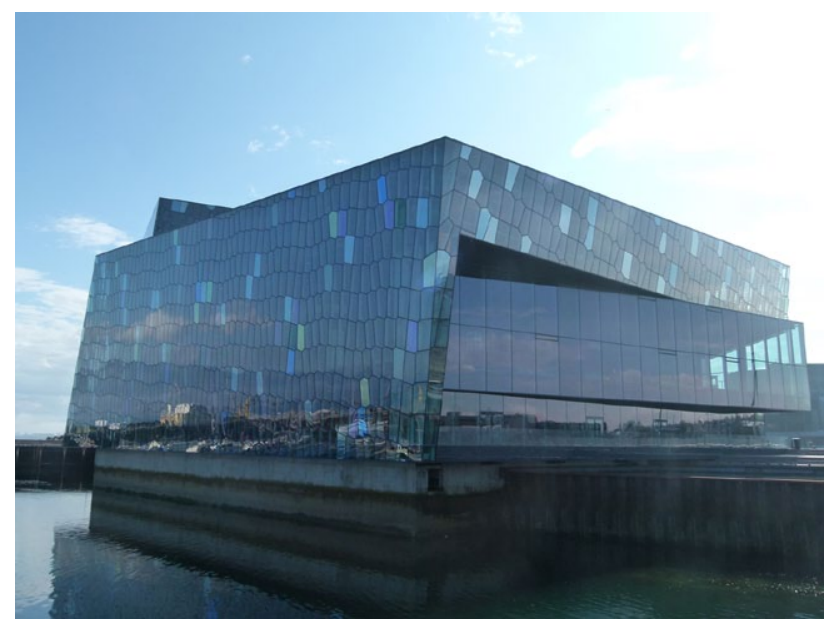

Figura 3 a: Hall and Conference Center de Reykjavik (Islandia) obra del arquitecto Henning Larsen (1925-2013). Una impresionante mole de aspecto etéreo gracias a las transparencias, reflejos y colores de sus planos de fachada.

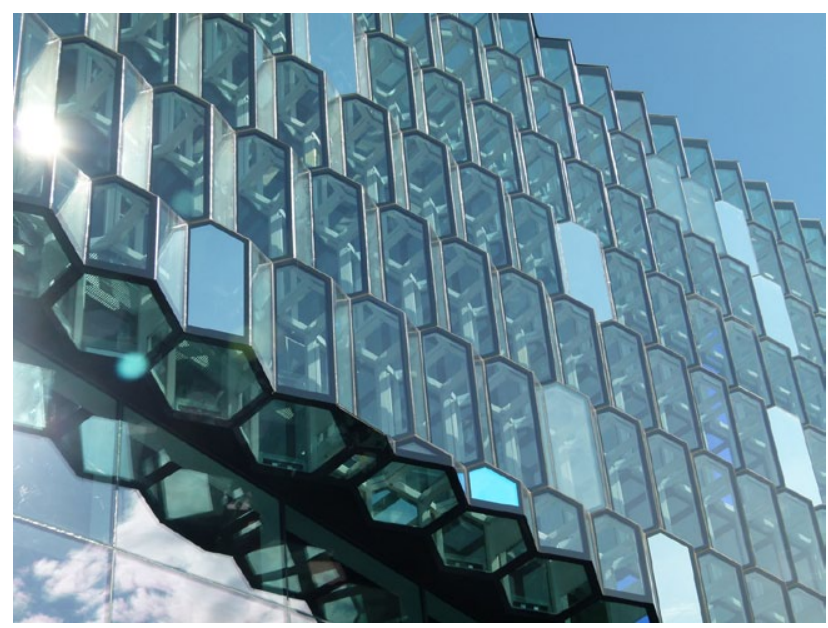

Figura 3b: La fachada está desarrollada alrededor de una estructura de prismas hexagonales, como la de las colmenas, que en este caso permiten una mayor captación y difusión de la luz al tiempo que favorecen el aislamiento térmico y acústico.

\section{ESCULTURA}

Los motivos representados pueden ser figurativos o abstractos y siempre son total o parcialmente tridimensionales.
Probablemente los primeros escultores de insectos o al menos, sin duda, los más conocidos, se encuentran en el Egipto clásico. En Luxor hay una gran escultura de un coleóptero de granito rosa que según la tradición se ha de rodear tres veces para que de suerte. También en la cultura Romana se esculpían insectos relacionándolos con los dioses, como en la escultura de La Diosa Madre, que está recubierta de testículos eviscerados y de un círculo de abejas en la parte inferior (Fig. 4).

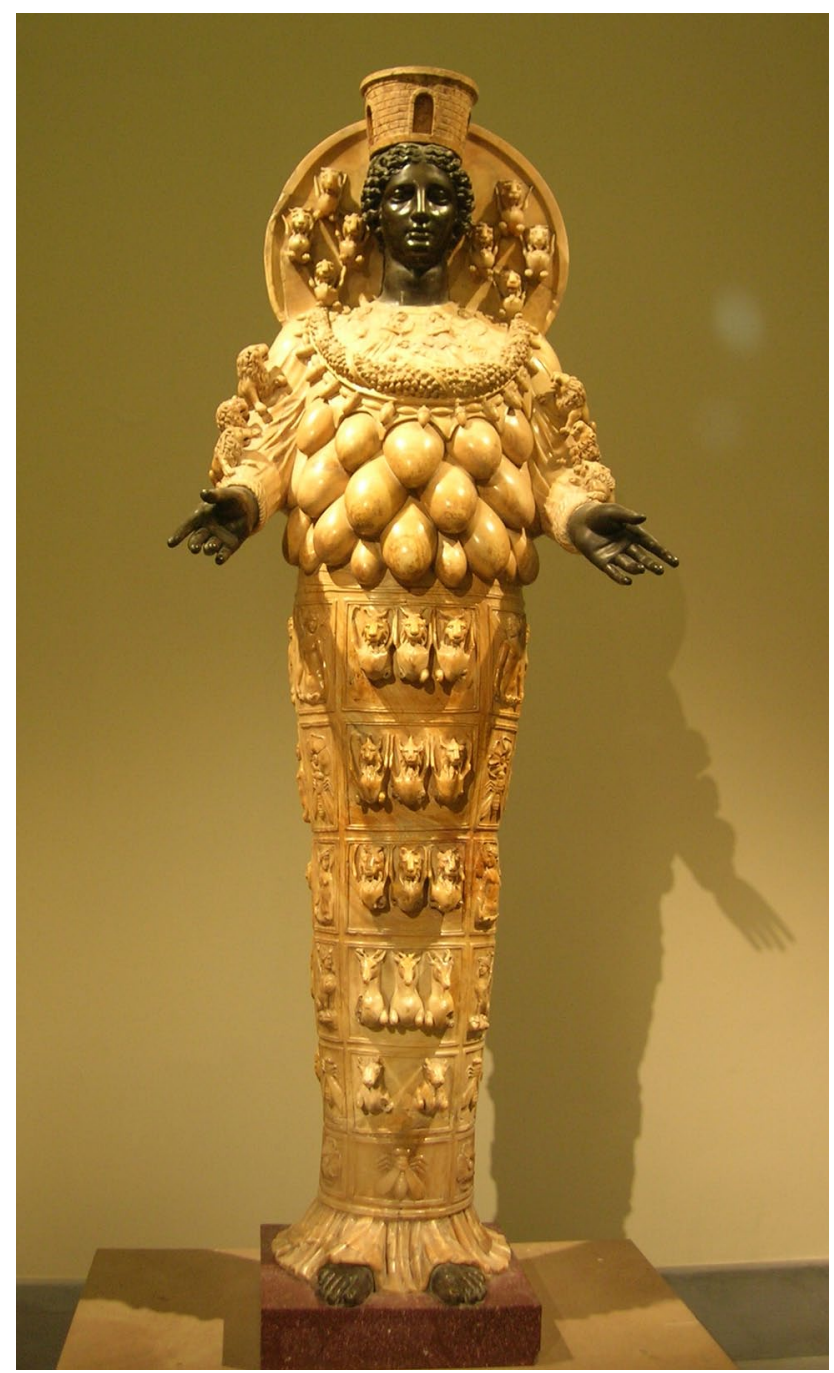

Figura 4: Diosa madre, las referencias a diosas madres, Magna Dea, son constantes en todas las épocas y culturas, en cada momento provistas de unos u otros atributos todos ellos tendentes a evidenciar la necesaria fertilidad para la subsistencia de la especie. En la parte inferior de ésta representación romana, se pueden apreciar unas abejas, también asociadas a la fertilidad. 
En el periodo clásico, los Barberini, grandes mecenas de la Roma Barroca, tenían como símbolo heráldico tres abejas, que han perdurado en numerosas esculturas. Pueden verse en La fuente del Tritón y en La Fuente de la Abeja en Roma (Fig.5), ambas obras de Gian Lorenzo Bernini (1598-1680), encargadas por el Papa Urbano VIII (1568-1644) miembro de dicha familia (AA. VV, 2000)

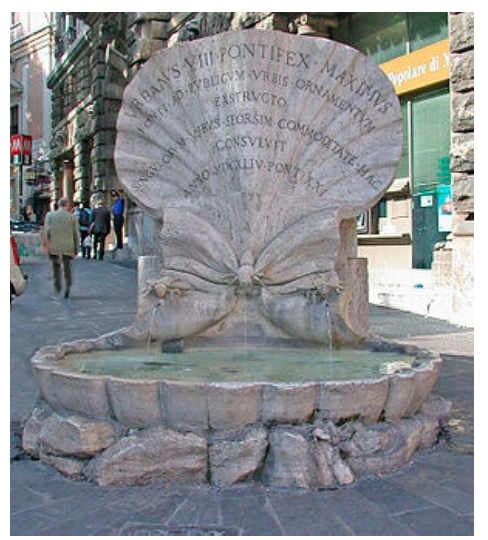

Figura 5: Fuente de la Abeja / Fontana, della Api, construída en 1644, originalmente situada en una esquina del Palazzo Soderini, en el cruce entre la Vía Felice Sixtina y la Piazza Barberini, servía prioritariamente como abrevadero de caballos. En 1870 se trasladó a la esquina de Vía Véneto con la Piazza Barberini, en Roma.

En el modernismo escultórico, real o inspirado, es habitual esculpir insectos. Un ángel con alas de mariposa es perfectamente distinguible en la fachada del Reial Cercle Artístic (fundado en el año 1881). Se utilizan los atributos de un insecto para conferirlos a una figura, en este caso de tono angelical y evocadora de la inspiración artística (Figs. 6a y b).

Edificios más modernos, como el Colegio de Aparejadores de Barcelona está coronado desde 1993 por un gran saltamontes obra de los artistas Joan Brossa (1919-1998) y Josep Pla-Narbona (1928) (Figs. 7a y b).

Artistas como el belga Jan Fabré (1958), utiliza de forma recurrente los insectos ya sea como motivo en sus esculturas e incluso como el material usado para elaborar las propias esculturas, hecho que ha sido criticado por algunos naturalistas, ya que implica la muerte de numerosos insectos, controvertido comportamiento en el que no profundizaremos en esta

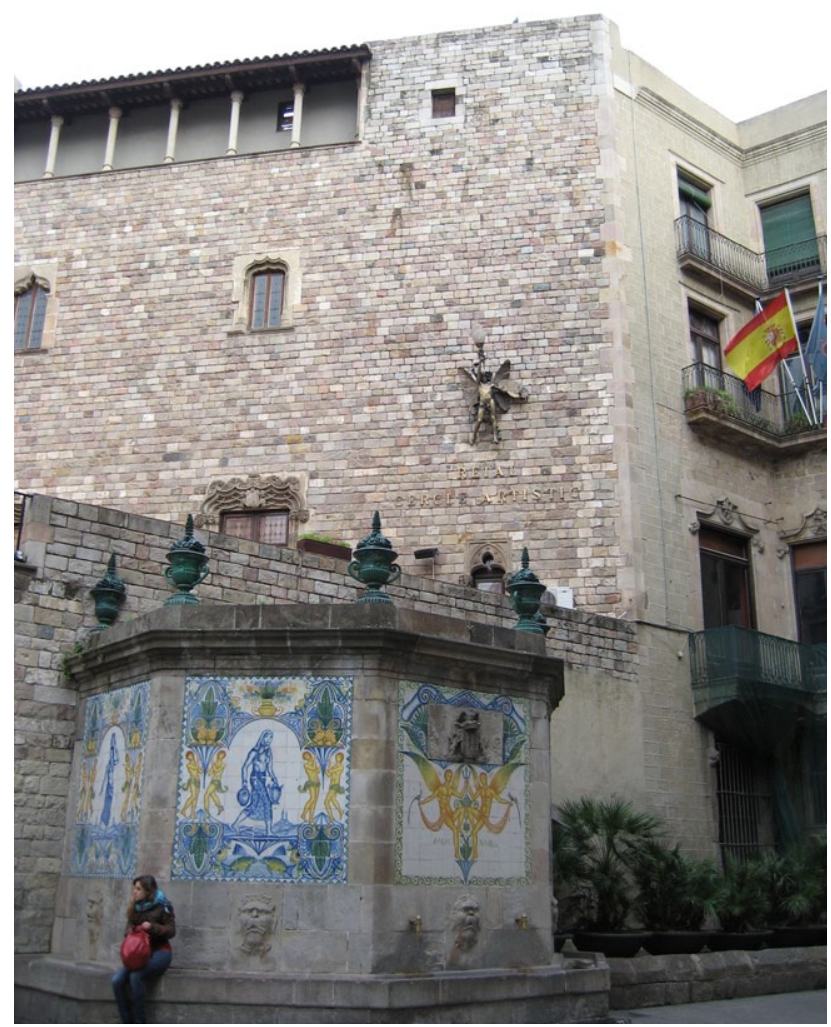

Figura 6 a: Reial Cercle Artístic de Barcelona, la sede mira al Portal del Ángel y ocupa el Palau dels Comtes de Pignatelli y la antigua Casa Bassols (XVI-XVII) Aquí tenemos un ejemplo de la utilización de los atributos de un insecto para conferirlos a la figura que preside el volumen arquitectónico.

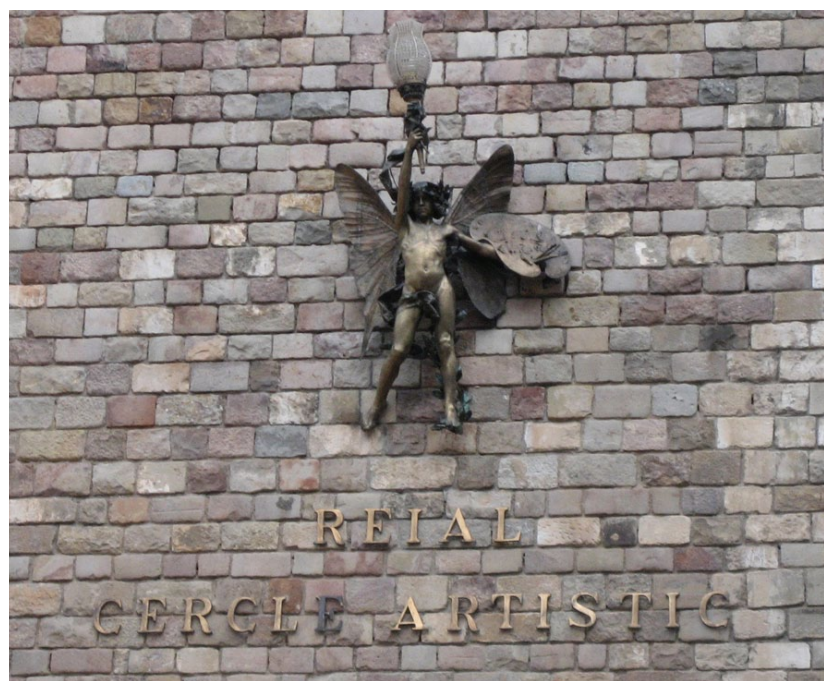

Figura 6 b: La escultura se denomina el Genio Alado o Genio de las Artes (1900) es obra de Josep Montserrat i Portella (1860-1923). Una escultura en bronce fundido realizada a precio de coste, como colaboración al Real Circulo, por la Fundición Masriera. 


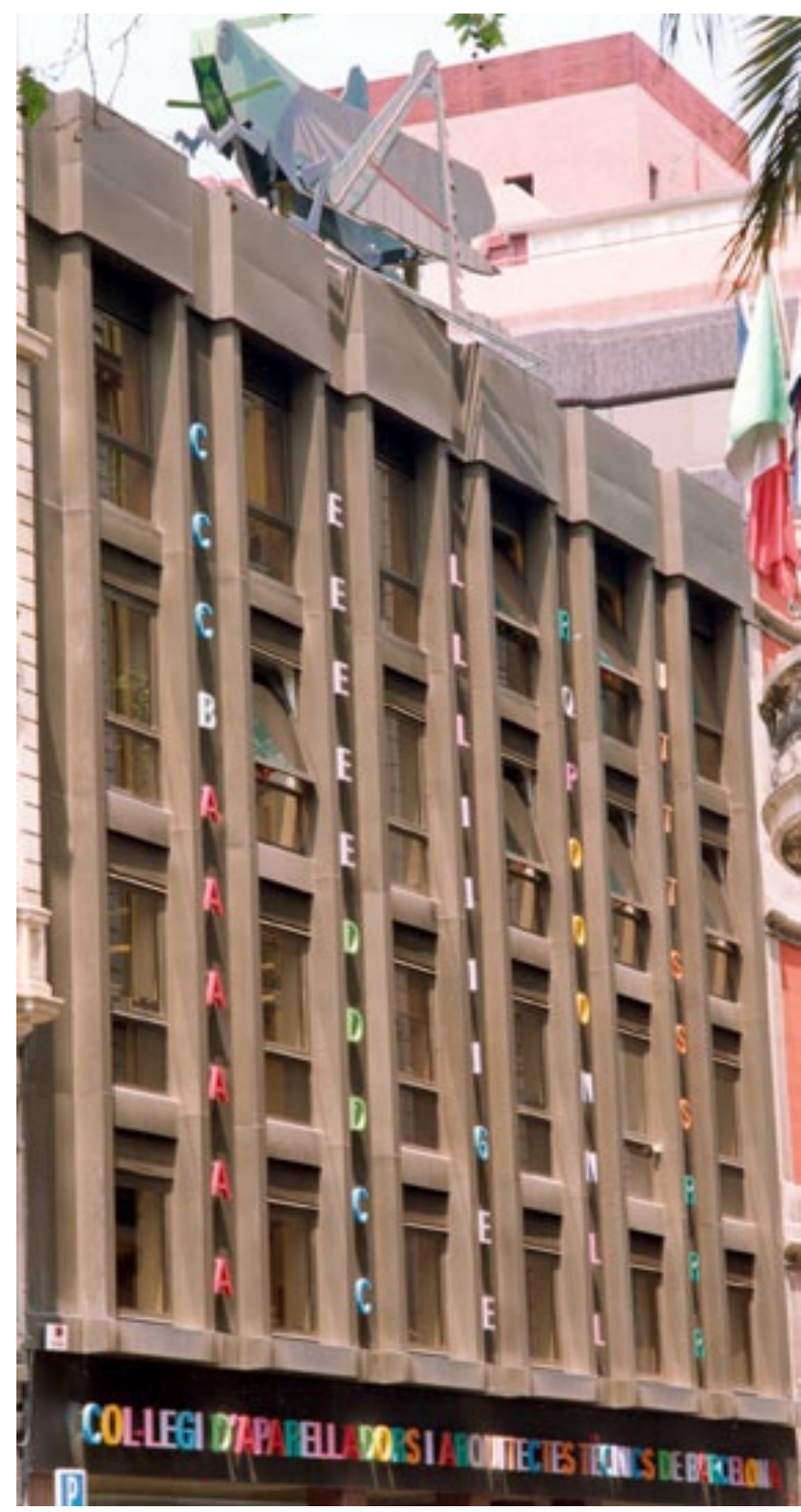

Figura $7 \mathrm{a}$ : Colegio de Aparejadores y Arquitectos Técnicos de Barcelona, la intervención plástica rematada por el saltamontes es una reconocible "poesía visual" de Joan Brossa.

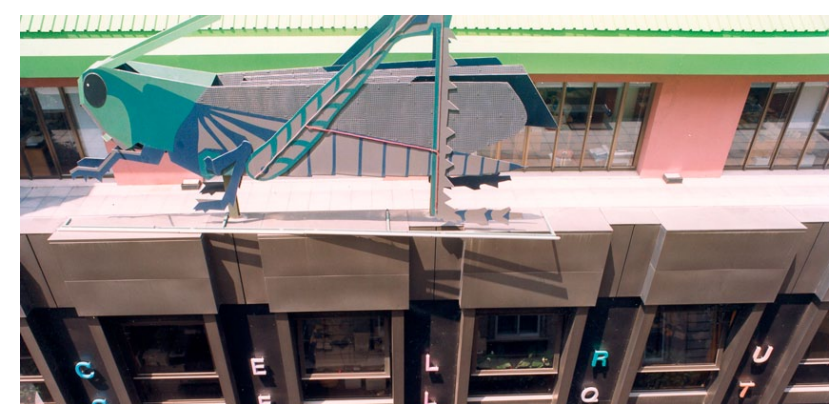

Figura 7 b: Detalle del saltamontes polícromo realizado en acero Corten. ocasión pero que debe ser tenido en cuenta por las implicaciones de todo tipo que puede tener. Por el contrario sí podemos decir ahora que Fabré es, así se declara, un gran admirador de los insectos.

Numerosos artistas actuales también se inspiran en los insectos sin utilizarlos de forma tan explícita y utilizan todo tipo de materiales como piedra, metales, cerámica, madera, materiales vegetales, papel, cristal, etc..., en sus creaciones.

\section{PINTURA}

Para empezar con la pintura, una referencia a un grabado prehistórico, el de la Cueva de las Arañas $(8000 \mathrm{aC})($ Fig. 8) en la que se ve una figura humana recolectando la miel de una colmena silvestre.

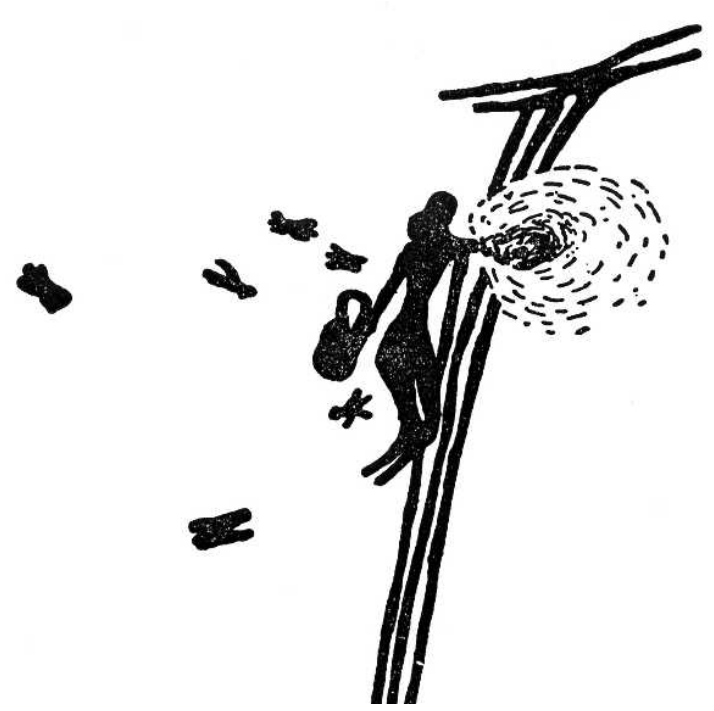

Figura 8: Cueva de las Arañas (8000 aC), una de las primeras representaciones de insectos que pone de manifiesto su aprovechamiento por los humanos.

Como en otras disciplinas a lo largo de la historia, la utilización de los insectos en la pintura ha variado. En ocasiones tiene un significado esotérico, simbólico y trascendental, y su representación depende del gusto, tendencia estética o estilo del pintor, así como de sus conocimientos naturalistas. En otros por el contrario parece una opción más aleatoria que intencional o meditada. El tipo de representación con la que se muestran depende de la época en que se pintaron. 
Iniciamos este acercamiento con el ejemplo de la pintura flamenca del siglo XVI, en ella los insectos representan los aspectos más negativos de la vida, en esencia, el pecado y la muerte. De ahí que en la inmensa mayoría de ocasiones aparecen como seres monstruosos o como símbolo de lo espiritual oscuro y esotérico, negativo y tenebroso, cabalístico y mágico, críptico y simbólico. Por contraposición en escuelas, estilos o géneros surgidos más tarde, como el de la "Naturaleza Muerta" (s-XVI y XVII), los insectos ocupan un papel relevante, ya sea discreto o evidente, como elemento de constatación de lo armónico e integrador tal y como se presenta en la propia naturaleza.

Entre los pintores flamencos una parada en la figura de Hieronymus Bosch "El Bosco" (14501516), el cual en la parte correspondiente al "Infierno" de su obra "El jardín de las delicias" pintó seres-mariposas de aspecto diabólico e imposibles de determinar. Parece ser que esta obra tiene un gran contenido y valores simbólicos (Montserrat, 2009 a). En la obra de otro pintor flamenco, Pieter Brueghel "El Viejo" (1525-1569) hay numerosos insectos reales o ficticios, en especial destacan en el cuadro titulado "Caída de los ángeles" en la que aparecen una serie de seres monstruosos resultado de la conversión de los ángeles en seres fantásticos mezcla de demonios y peces, reptiles e insectos (moscas, alas de mariposas entre otros) (Fig. 9).

En paralelo con estos valores esotéricos o recreaciones simbólicas, en el género de "Naturaleza Muerta" los insectos representados entre jarrones, guirnaldas y bodegones son perfectamente identificables y constituyen un elemento más del cuadro, un reflejo más de la propia naturaleza que los ampara, en la que habitan y de la que forman parte sin mayores trascendencias. En estos cuadros están representados muchos grupos (coleópteros, lepidópteros, dípteros, odonatos, himenópteros, ortópteros, neurópteros y diversas larvas y orugas). Entre los autores que han cultivado este estilo pictórico está Jan Brueghel de Velours (1568-1625) el cual recrea en sus obras de forma muy fidedigna numerosos grupos de insectos. En su obra "Guirnalda con la Virgen y el Niño" podemos identificar hasta 23 insectos (Gurrea \& Martín Cano, 2007). También relevante es la obra

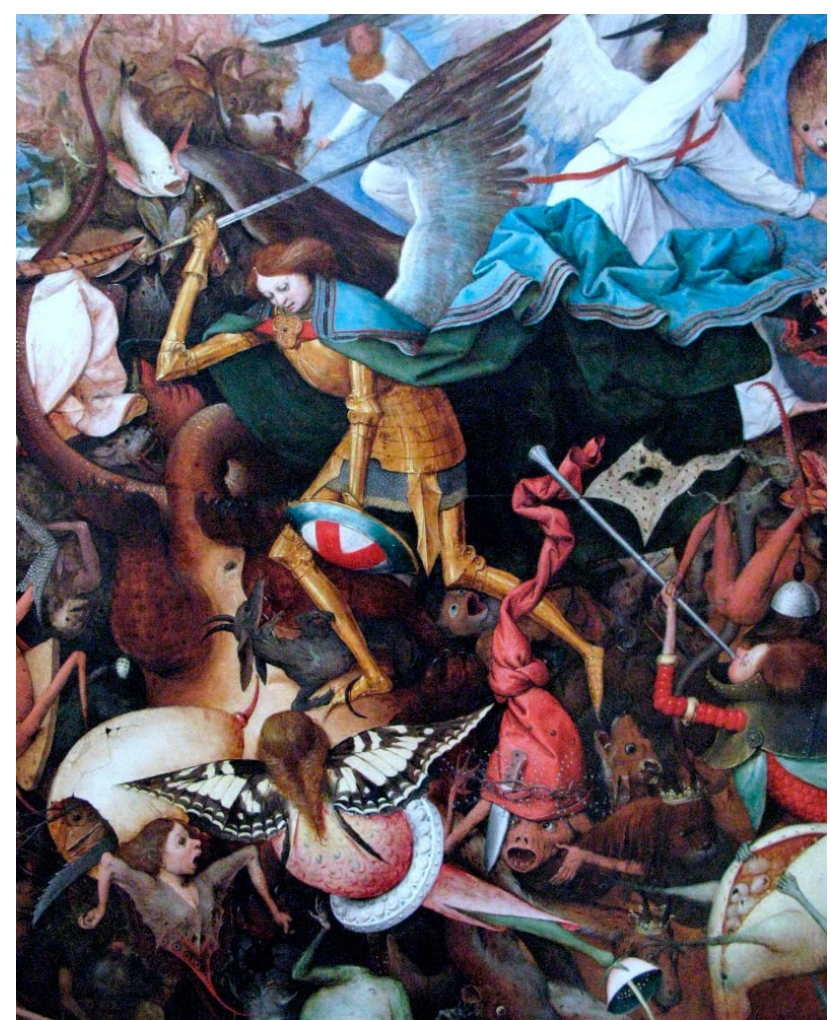

Figura 9: Detalle de la "Caída de los ángeles", 1562. Óleo sobre tabla de 117 X $162 \mathrm{~cm}$. de Pieter Brueghel "el Viejo". Conservado en los Museos Reales y de Bellas Artes de Bruselas en Bélgica.

del holandés Jan van Kessel (1626-1679) que usó como motivo de sus naturalezas muertas los insectos, a destacar la obra titulada "Insectos en una losa de piedra" (Fig. 10).

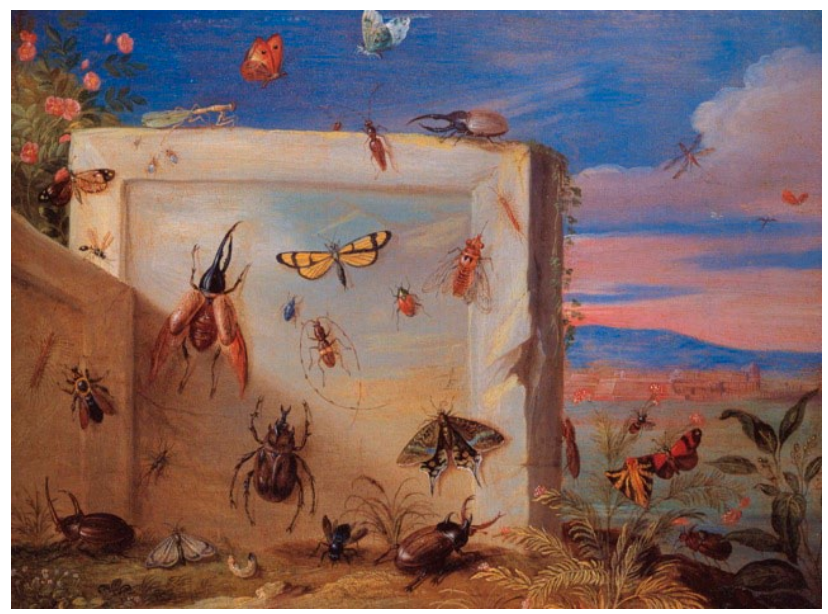

Figura 10: "Insectos en una losa de piedra" (1660-1670). Óleo sobre tela de Jan van Kessell, conservado en el Kunstmuseum de Basilea, Suiza. 
Volviendo al valor simbólico de los insectos en algunas pinturas de Vírgenes o Madonnas se observa la figura de una mosca que pueden tener significados diferentes. En general las moscas representan el pecado del que Cristo vino a redimirnos y este puede ser el significado en las vírgenes góticas, las flamencas y las ibéricas. Sin embargo en los cuadros de Carlo Crivelli (1430-1495), la presencia de estos insectos pueden indicar que la madonna representada en Maria Magdalena y no la Madre de Cristo (Ferrer, 2009)

Otra figura a destacar es Anna Maria Sibylla Merian (1647-1717), la primera mujer que se dedicó a la pintura naturalista, a pintar insectos y flores, de forma sistemática, precisa, descriptiva..., en definitiva, científica. Pasó desapercibida en su época, pero siglos después de su muerte se reconoció su obra y en señal de homenaje su cara figuraba en los billetes de 500 marcos alemanes (Fig. 11).

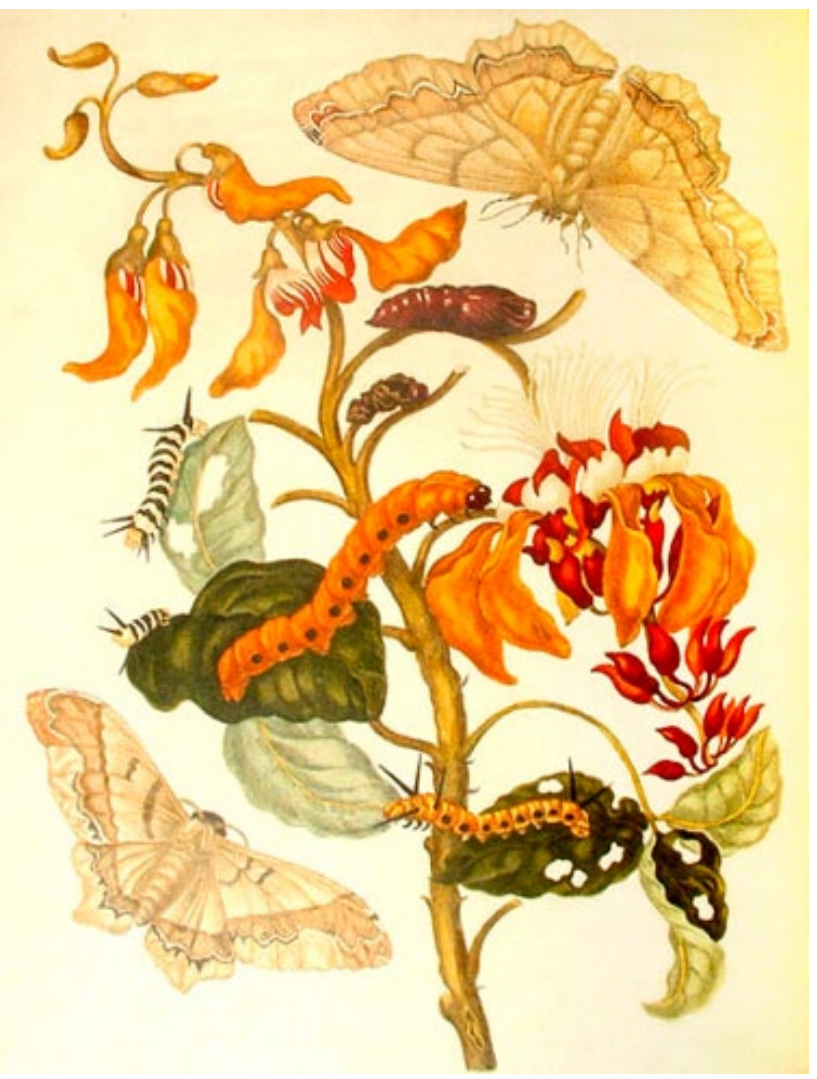

Figura 11: Anna Maria Sibylla Merian, reproducimos una acuarela en las que las mariposas son protagonistas (1701), de 30 X $40 \mathrm{~cm}$, conservada en el St Petersburg Archiv. Der Akademie der Wissenschaften.
Dando un Nuevo salto en esta cronología esporádica de insectos y pintura, mencionaremos al holandés post-impresionista Vincent Willem van Gogh (1853-1890) que pintó escarabajos y mariposas de vivos colores como protagonistas de sus obras o para realzar los paisajes en los que los sitúa (Fig. 12) (Montserrat 2009 b)

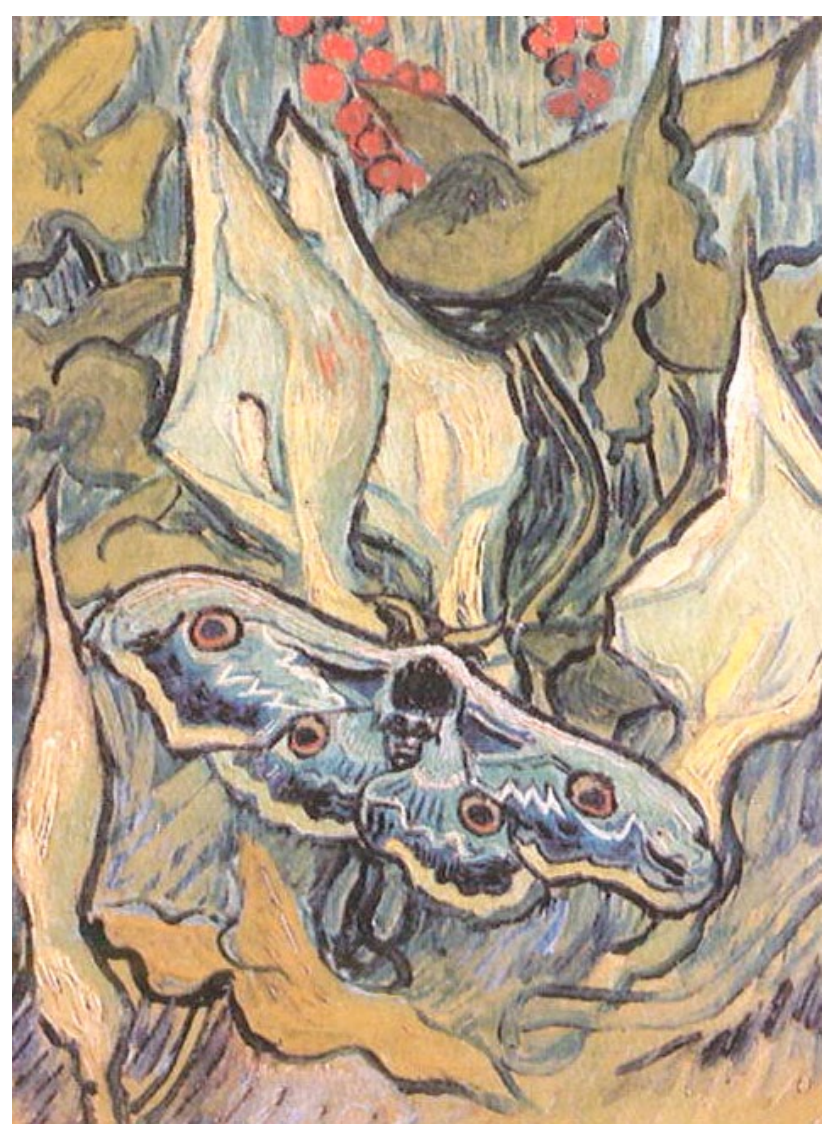

Figura 12: Reproducimos la obra Emperor Moth, (1889), 33,5 X 24,5cm, óleo sobre lienzo conservado en el Van Gogh Museum de Ámsterdam. (Montserrat 2009b)

Pero no todos son presencias de hace cientos de años. Entre los artistas españoles más famosos están Pablo Picasso (1881-1973) y Salvador Dalí (1904-1989) (Fig. 13). En ambos casos los insectos que pintan son muy fieles a los modelos, sin caer en sus influencias estilísticas más habituales. También Joan Miró (1893-1983) pinta insectos, en este caso de forma surrealista, como corresponde a su estilo pictórico. Una de sus obras es la titulada "Diálogo de los insectos", es habitualmente citada y reproducida.

Para finalizar este apartado y con la idea de dar una visión de algunos de los estilos pictóricos 


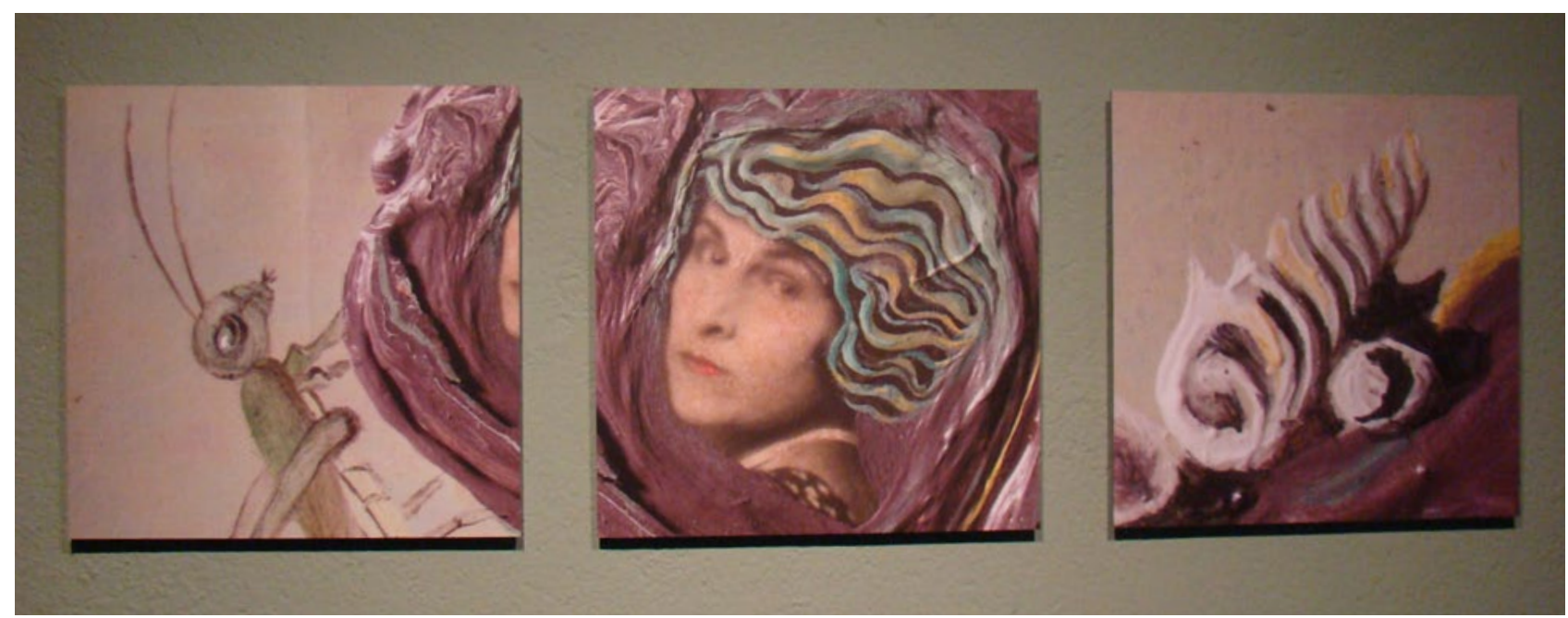

Figura 13: Los insectos son habituales en la obra de Salvador Dalí, forman parte de sus obsesiones oníricas y aparecen como complemento o como protagonistas en muchas de sus obras. En la que reproducimos, expuesta en su TeatroMuseo de Figueras, un saltamontes comparte protagonismo con otra de sus musas sempiternas, Gala.

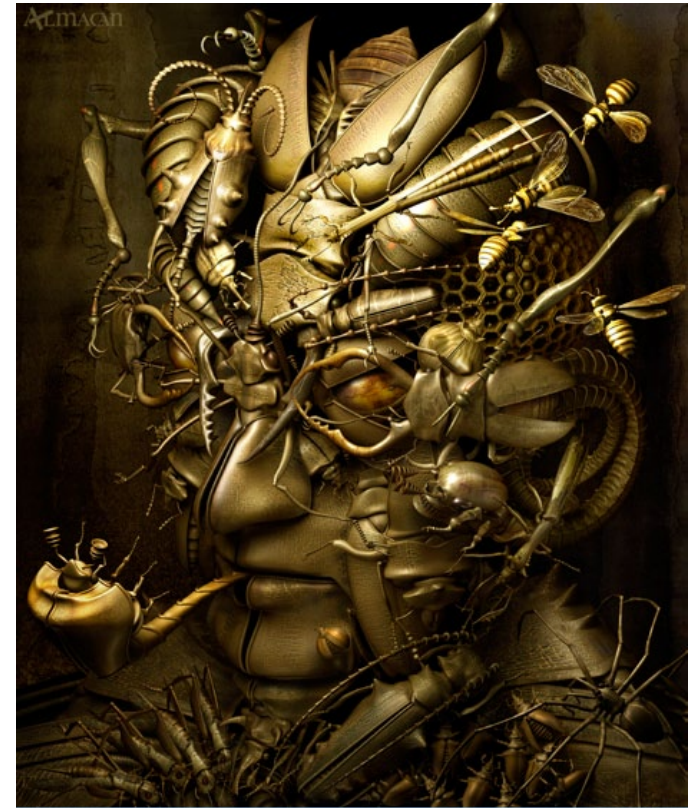

Figura 14: Kazuhiko Nakamura retoma en sus obras la construcción de una realidad a partir de otras preexistentes y con sentido propio como el caso de uno de sus más destacados y conocidos precursores Giuseppe Arcimboldo (1527-1593).

-contemporáneos mencionaremos tres ejemplos. La obra del pintor japonés hiperrealista Kazuhiko Nakamura (1961) (Fig. 14) representante del movimiento actual del "surrealismo mecánico". Sus cuadros parecen más una escultura que una pintura y este efecto lo consigue jugando con los elementos que utiliza para elaborarlas, siendo en algunos casos

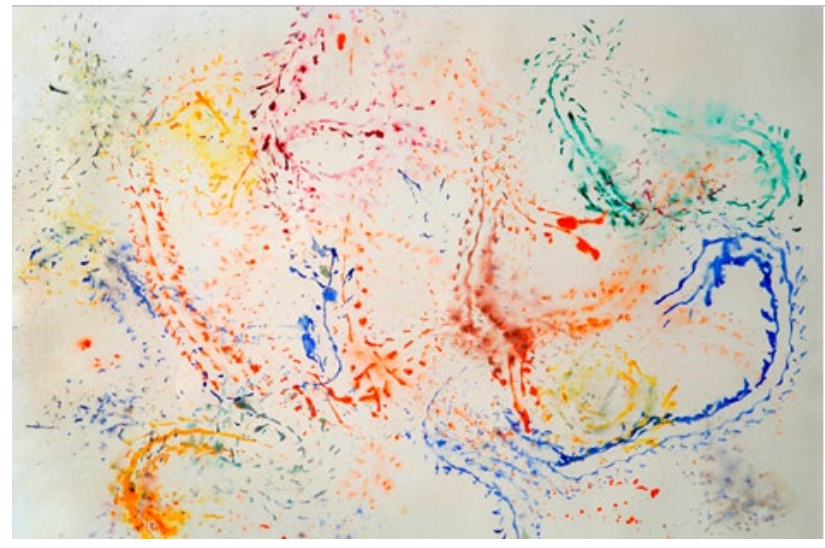

Figura 15: Vemos en esta creación plástica de Steven Kutcher, los rastros que en sus movimientos por el lienzo húmedo van dejando varios insectos.

insectos. Por la otra nos situamos ante los "Insectors pintores!”, de Steven Kutcher, polifacético personaje que ha desarrollado una técnica de adiestramiento a partir del cual sus insectos "pintan" en una singular recreación del "action painting” (Figura 15).

Y finalmente los pintores anónimos, los grafiteros, que también recrean a los insectos en sus obras (Fig. 16). 


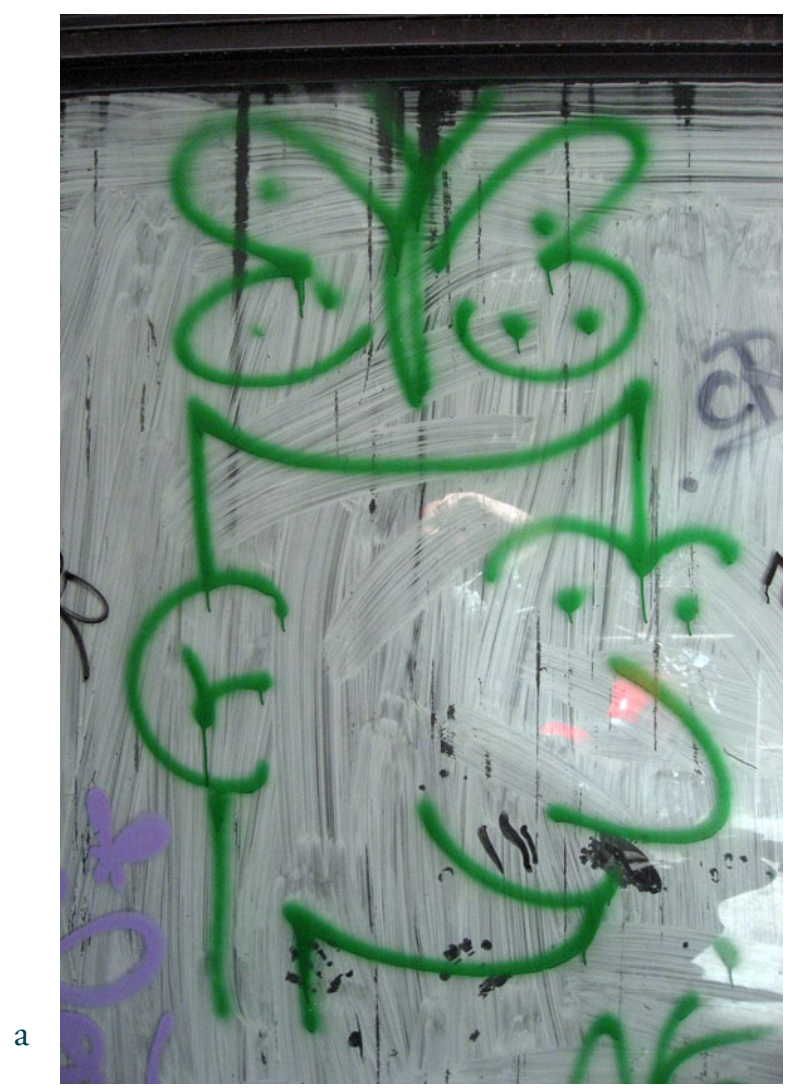

Figura 16 a y b: También los grafiteros, usan insectos en sus obras, a veces enfocadas como denuncias a la sociedad o como aportaciones plásticas más personales (a). Siempre debemos estar atentos porque son efímeras y en muchas ocasiones otros grafiteros se encargan de que desaparezcan (b)

b

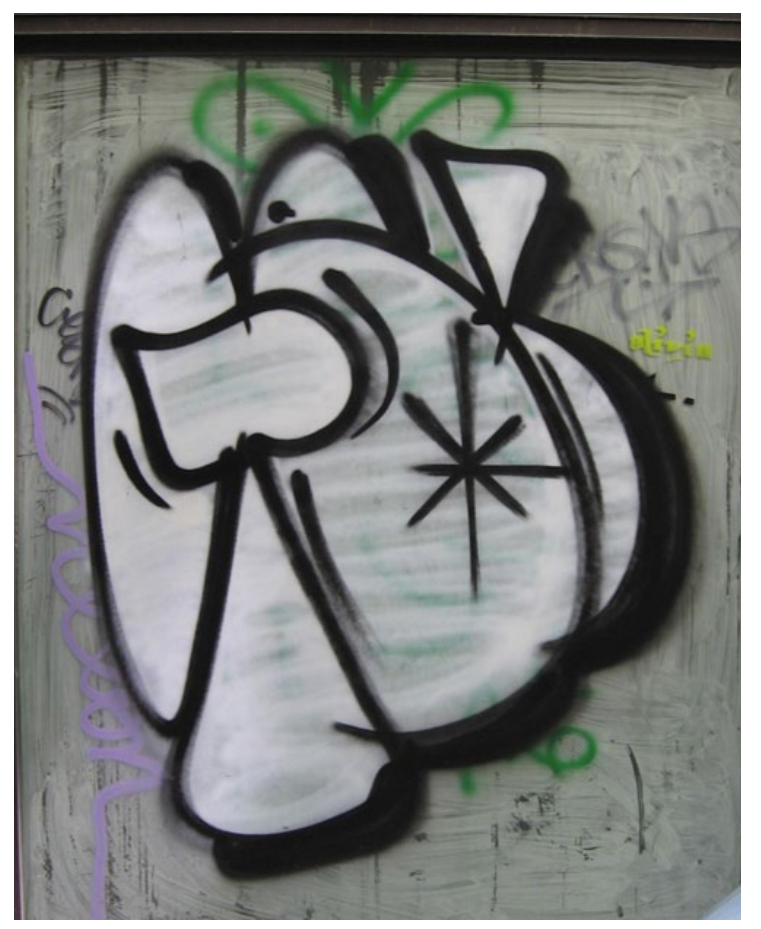

No podemos cerrar este apartado sin aconsejar la visita al Museo del Prado guiados por el trabajo de Gurrea y Martin Cano (2007).

\section{MÚSICA (INCLUYENDO TEATRO)}

La música (incluyendo el teatro) es muy importante en todas las sociedades, desde las más primitivas, en donde tiene en la gran mayoría de los casos un sentido ritual, hasta las más evolucionadas en las que se convierte por sí misma en rito o manifestación de identificación del clan al que se pertenece.

La vida de los insectos, la metamorfosis, su biología y comportamiento han sido objeto de letras de canciones y de obras más extensas, en las que se transmiten los valores que representan, ya sean positivos o negativos. No todos los grupos de insectos están igualmente representados en la música, siendo los himenópteros, lepidópteros y dípteros, los más utilizados (Coelho, 2000).

En la música los insectos están presentes fundamentalmente bajo tres perspectivas. En la primera (a) recoge y emula de una forma más o menos fidedigna los sonidos de aquellos que emiten. En la segunda (b), aparecen los nombres de los insectos en las letras tanto en sentido descriptivo como metafórico o, en otras ocasiones trasladando los atributos reales de los insectos, a otros ficticios, los personajes de la obra. La tercera perspectiva (c) es esencialmente anecdótica, ya que aparecen los insectos, sus nombres o como referencias, sin un sentido conceptual o lógico estricto.

La perspectiva (a) está magistralmente ejemplificada con "El vuelo del Moscardón” (Fig. 17), de Rimsky-Korsakov (1844-1908) y el Dúo del Moscardón de la opereta satírica "Orphée aux Enfers", (Fig. 18) , compuesta por Jacques Offenbach (18191880) (Batta \& Neef, 2000).

Como ejemplos de la perspectiva (b) tenemos la Ópera Madame Butterfly, (Figs 19a y b), ópera trágica del compositor Giacomo Puccini (1858-1924), estrenada en 1904. En alguna zarzuela, género lírico español por excelencia también se hace referencia a los insectos, como por ejemplo en "Doña Francisquita”, con su "Zángano zumbador”. También hay, 


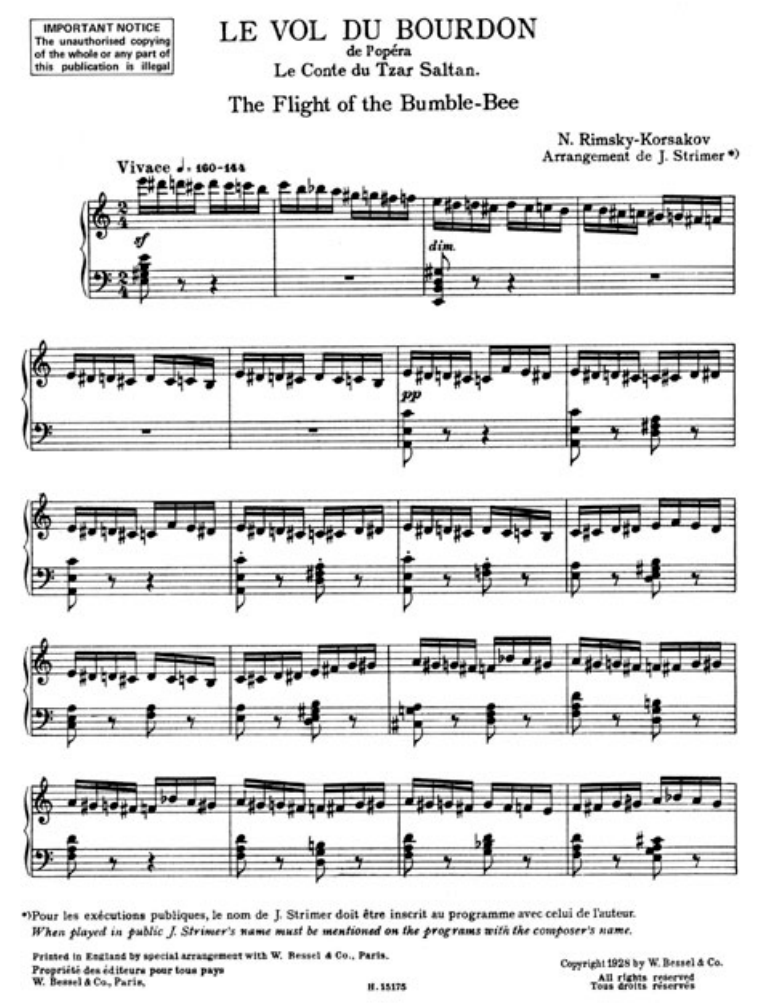

Figura 17: Primera página de la partitura de "El vuelo del Moscardón”, compuesto entre 1899-1900, esta pieza cierra el Cuadro I del Acto III.

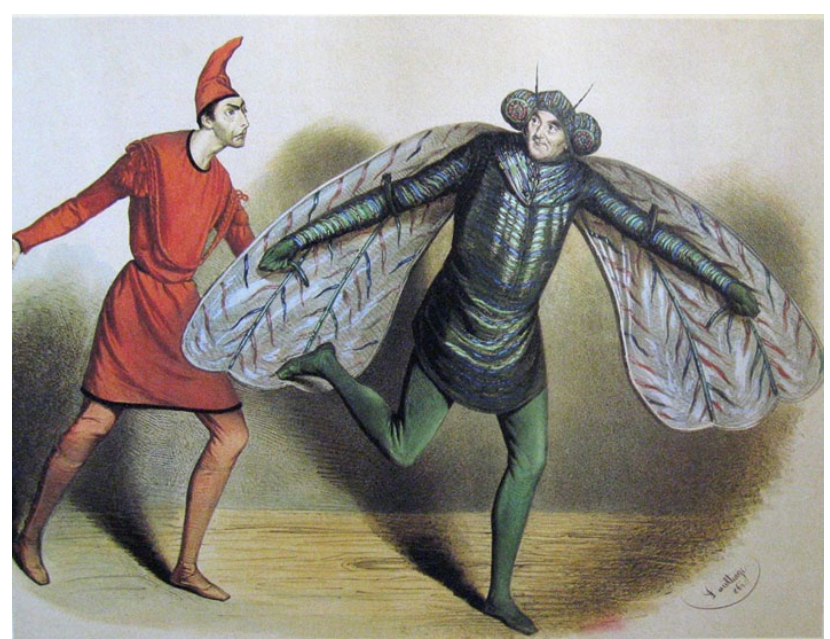

Figura 18: Ilustración de 1860 para la primera representación de Orfeo en los infiernos en el Carl Theatre de Viena. Representados los cantantes Johann Nepomuk Nestro (Júpiter) y Wilhelm Knaack (Estigia).
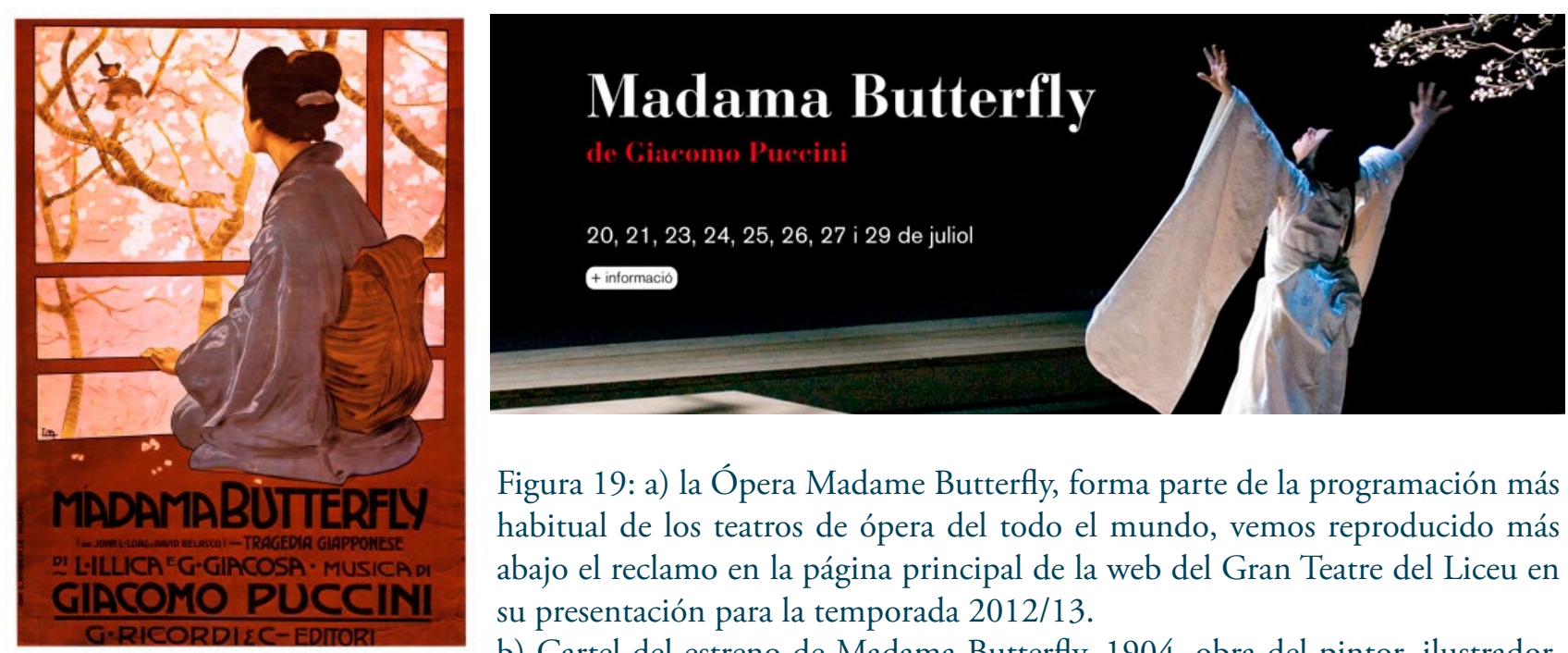

Figura 19: a) la Ópera Madame Butterfly, forma parte de la programación más habitual de los teatros de ópera del todo el mundo, vemos reproducido más abajo el reclamo en la página principal de la web del Gran Teatre del Liceu en su presentación para la temporada 2012/13.

b) Cartel del estreno de Madama Butterfly, 1904, obra del pintor, ilustrador, escenógrafo, diseñador de vestuario y gran cartelista e introductor del modernismo en Italia, Adolfo Hohenstein (1854-1928). 
un sin fin de canciones populares con nombres de insectos como la cucaracha, el grillo, las hormigas..., que son protagonistas de tonadillas conocidas y repetidas simpática y alegremente.

Hay muchos ejemplos de la perspectiva (c) y basándonos en el trabajo de Coelho (2000), sobre la música Rocks and Rolls, encontró que había 213 artistas con nombres de insectos, otros tantos álbums y 912 canciones en las que se hacía referencia a los insectos en los títulos. Los Beetles, los Bee Gees, The Iron Butterfly, Adam y de Ants y los Crickets, (Figs. $20 \mathrm{a}$ y b) son algunos ejemplos de grupos musicales. En el mencionado trabajo se pone de manifiesto que los grupos más utilizados tanto a nivel de grupos, como de álbumes y canciones son los himenópteros, los lepidópteros y los dípteros, aunque están representados la mayoría de los órdenes de insectos.
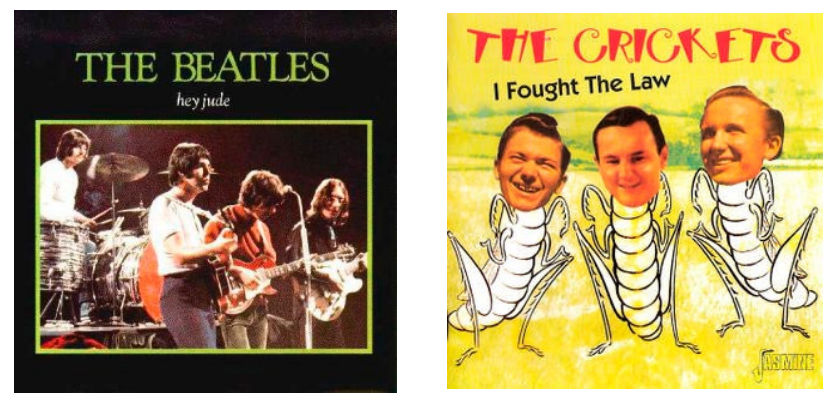

Figura 20 a : Beatles, (1962-1970) formada por John Lennon, Paul McCartney, George Harrison, Ringo Starr, el nombre se debe a John Lennon y a Stuar Sutcliffe primer bajista del grupo-, por el doble significado que tiene al leerse u oírse, escarabajo o música con ritmo de una u otra manera.

Figura 20 b: Banda de rock formada en los 50, en Lubbock, Texas, alrededor del cantautor Buddy Holly. Fue inspiradora en música y en nombre de The Beatles.

Siguiendo, como ya hemos explicado, la visión artes-mayores-clásica y situando el teatro en el ámbito de la música, citaremos algunas obras en las que los insectos son los protagonistas. La primera obra de teatro escrita por Federico García Lorca (1898-1942), es un drama infantil titulado, "El maleficio de la mariposa" (Fig. 21).

Producciones El Gallinero estrenó en 2008 "Insectarium, el circo de los Insectos", en el que los grandes números son "la ninfa de Libélula Cantora"
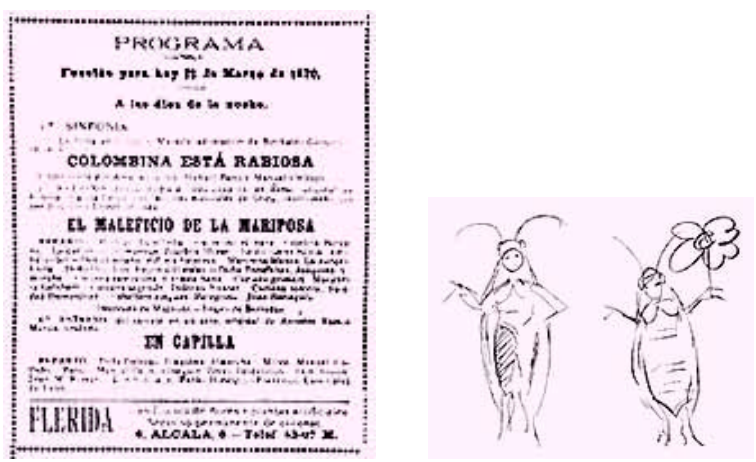

Figura 21 a y b: Cartel (a) y dibujo (b) originales de Federico García Lorca (1898-1942), para su "Drama infantil" titulado, "El maleficio de la mariposa".

y el "Bicho Bala"(un insecto atómico), son solo ejemplos pero nos permiten apuntar e identificar una presencia recurrente hasta la actualidad.

\section{DECLAMACIÓN (LITERATURA Y POESÍA)}

El concepto de declamación ha ido cambiando con los tiempos. Siguiendo con el tono de presentación general del presente artículo, tenemos que aclarar que en sentido clásico incluía la Literatura y la Poesía en una forma de presentación pública similar a la de nuestro teatro actual.

Por tanto al referirnos a la Declamación hablaremos aquí por extensión de Literatura que es el arte que tiene como instrumento la palabra.

Sin lugar a duda, es en la Literatura donde los insectos están mejor representados. Obras muy importantes, los incluyen en el título, en otras son tomados como modelo en el desarrollo de la trama, erigiéndose en metáforas de la condición humana, para los que se fijan en aspectos relativos a su comportamiento, biología, reproducción y otros muchos. Tampoco faltan las obras en las que los insectos son los protagonistas y otras en las que en un momento determinado se utilizan expresiones referentes a alguno de sus atributos: grácil como una mariposa, pesado como un moscardón, molesto como el zumbido de un mosquito, etc... desde la poesía japonesa antigua, "los haiku" hasta la novela moderna pasando por todo tipo de estilos como ya hemos indicado.

Comentaremos algunas obras de literatos recono- 
cidos a nivel mundial, que han utilizado los insectos como metáfora para contar sus historias. Hay que decir que alguno de ellos como Vladimir Nabokov (1899-1977), escribió obras entomológicas porque además de escritor era entomólogo precedido por Charles Nodier (1780-1844) y utiliza los insectos de forma regular en sus obras literarias como el cuento titulado "Sybilla Merian" (1932) o "El hombre y la hormiga", Alexis Saint-Léger (1887-1975) entre otros (Moret, 1997). También comentaremos la figura de Ulisse Aldrovandi (1522-1605) considerado como autor de la primera enciclopedia entomológica (Figs 22a, b y c),

Ulisse Androvandi (1522-1605) fue un científico y naturalista italiano, autor de una de las dos Enciclopedias Zoológicas que marcan la diferencia entre la Zoología de la antigüedad clásica y la moderna. El otro autor al que nos referimos es Conrad Gessner (1516-1565) que fue un naturalista y bibliógrafo suizo.

Ulisse Aldrovandi es autor de una gran Enciclopedia de Zoología, y publicó en vida el volumen dedicado a los insectos (1602) y también los de aves (1599, 1600 y 1603). Los restantes volúmenes, fueron publicados por sus discípulos entre 1606 y 1642. El volumen de insectos constituye una de las bases más sólidas de la Entomología moderna y va acompañado de ilustraciones xilográficas basadas en los originales coloreados al agua por el propio Aldrovandi, que se conservan en Bolonia. (Bellés, 2000; http://entomologia.rediris.es/aracnet/6/precursores $2 /$ )

Nuestro recorrido por la literatura comienza por las fábulas de Esopo, una de las primeras referencias de los insectos en la literatura -aunque no está probada su existencia como persona real algunos autores coinciden en que vivió alrededor del 600 a C -. Mencionaremos entre sus fábulas las tituladas "El águila y el escarabajo" y "La cigarra y la hormiga" (Figs 23a y b).
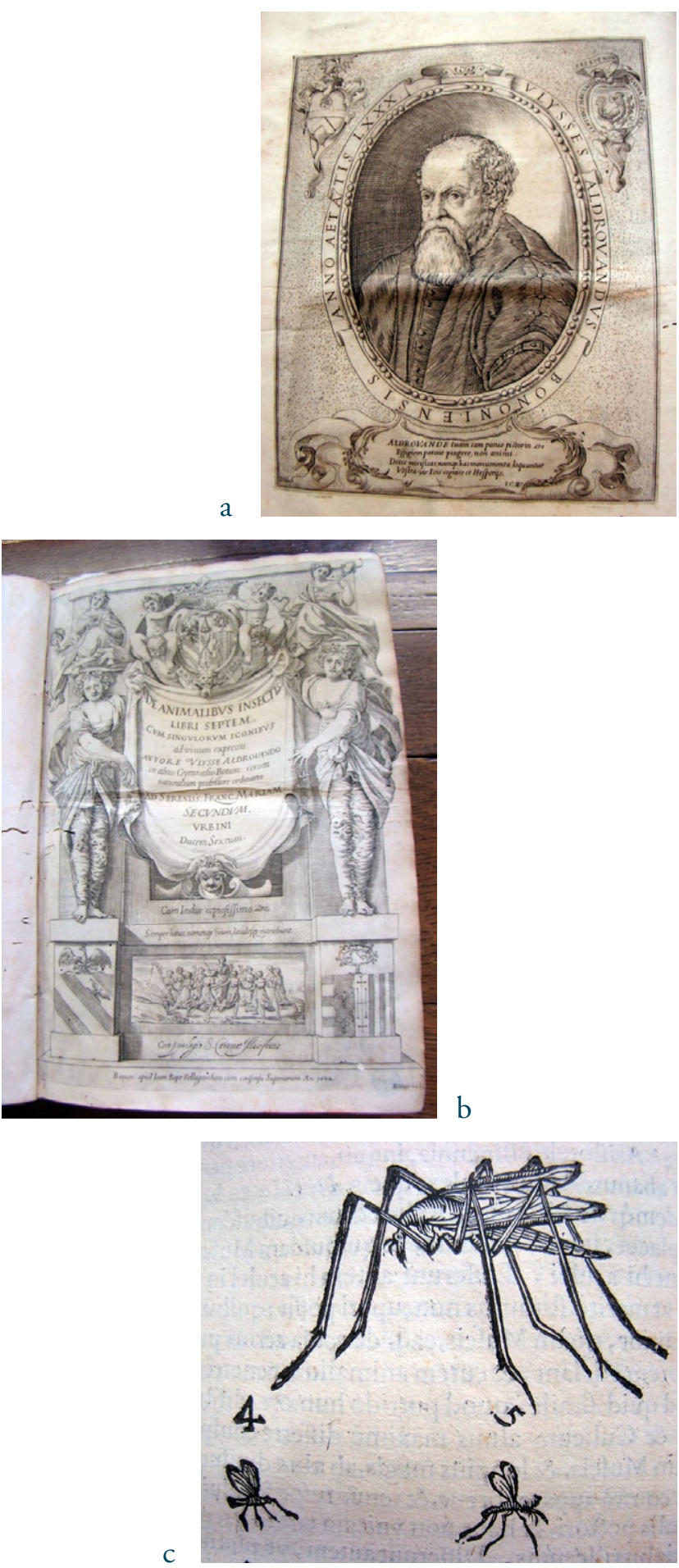

Figura 22 a, b y c : de Ulisse Aldrovandi (1522-1605) considerado como autor de la primera enciclopedia entomológica. Figura 22 a: retrato del autor. Figura 22 b: portada de la obra. Figura 22 c: detalle de una de las ilustraciones, grabados xilográficos, realizados según sus dibujos; a destacar cómo evidencia la escala entre las diferentes especies.

Fotografías realizadas al ejemplar existente en la Biblioteca de la Universidad de Barcelona. 

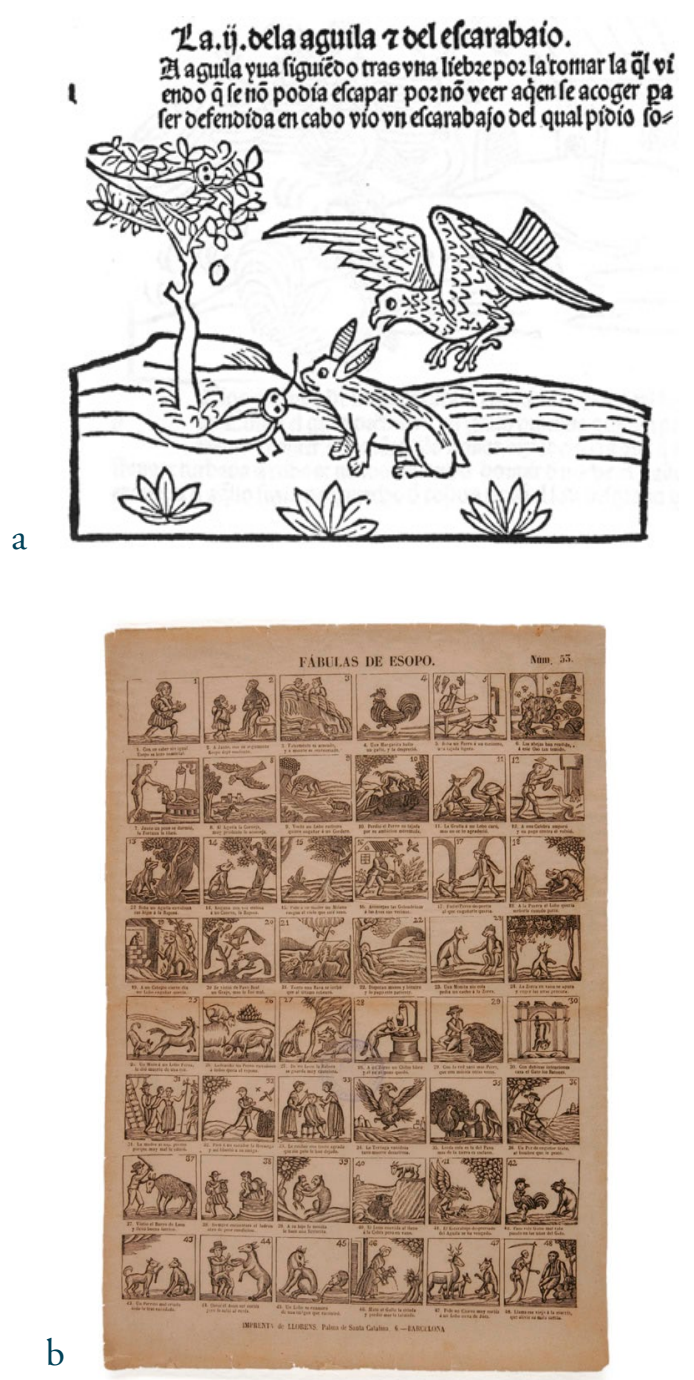

Figura 23 a y b: Fábulas de Esopo. Figura 23 a Xilografía que ilustra el águila y el escarabajo de Esopo, proviene del facsímil de Emilio Cotarelo y Mori, RAE. Madrid, 1929. El original titulado "La vida de Ysopet con sus fábulas historiadas", es de Juan Hurus y fue editado en Zaragoza en 1489. Figura 23 b: Aleluya, "Fábulas de Esopo", papel $45 \times 30 \mathrm{~cm}$, proviene del animalario recopilado por la Secretaría de Estado de Cultura, número de inventario 42235 Barcelona.

Seguimos el recorrido con un listado de autores y obras relevantes ya sean personajes principales, apariciones esporádicas, aproximaciones metafóricas...:

Jonathan Swigt (1667-1745), "Los viajes de Gulliver" (1726).

Bernard de Manderville (1670-1773) "La fábula de las abejas" o "Vicios privados, públicos beneficios" (1914).
Edgar Allan Poe (1809-1849): "La esfinge" (1846) y "El escarabajo de oro" (1843).

Frank Kafka (1883-1924) "la Metamorfosis" (1915)

Saint-John Perse (Alexis Saint-Léger) (18871975), Premio Nobel de Literatura, 1960. "Elogios" (1908)

William Golding (1911-1993), Premio Nobel de Literatura en 1983. "El señor de las moscas" (1954) (Figura 24).

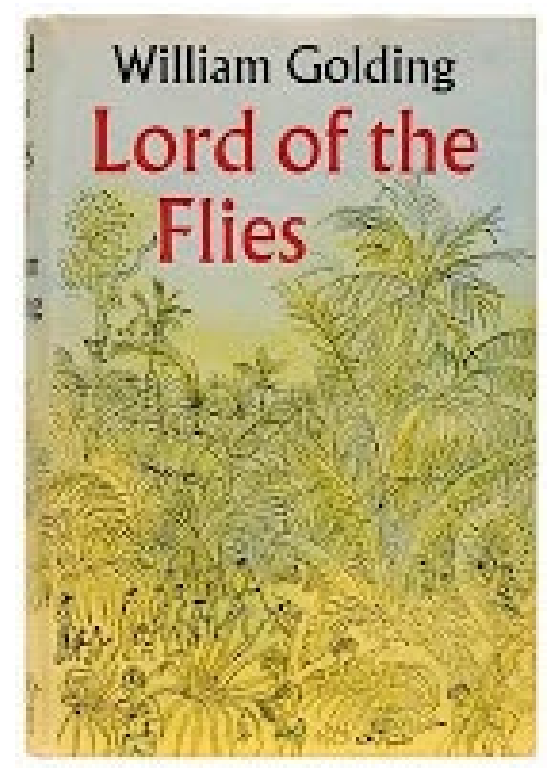

Figura 24: Portada de la primera edición de "El señor de las moscas" de Faber and Faber, London, 1954.

Roger Callois (1913-1978) "La mantis religiosa" (1934) , "El mimetismo y la psicanéstia legendaria" (1935) y de "El mito y el hombre" (1938)

Camilo José Cela (1916-2002) Premio Nobel de Literatura en 1989. "La colmena", editada en Buenos Aires (1945/46) y que no se publicó en España hasta 1951 por problemas con la censura franquista.

Kobo Abe (1924-1993), "La mujer de la arena" (1962).

Gabriel García Márquez (1927-) Premio Nobel de Literatura (1982). "Cien años de Soledad" (1967).

Thomas Harris: (1940-) "el silencio de los corderos" (el silencio de los inocentes en Latinoamérica), (1998)

Haruki Murakami (1949-) "Sauce ciego, mujer dormida" (1996), compuesta por veinticuatro relatos, uno de ellos es el titulado "La luciérnaga". 
En poesía, al igual que en la literatura, mencionaremos algunas obras famosas en las que los insectos son utilizados como elementos para expresar sentimientos o para describir situaciones.

Los Haikus, son una forma de poesía tradicional japonesa. Algunos de los haikus mencionan en los versos insectos, ya sea formando parte del título o no. (http://es.wikipedia.org/wiki/Haiku). Entre los poetas que han cultivado los haikus está Matsuo Bashô (1644-1694) y Kobayashi Issa (1763-1827).

John Donne (1572-1631). Escribió el poema amoroso "La pulga", en el que valiéndose del comportamiento de la pulga, lo utiliza como una metáfora de la relación amorosa.

José Asunción Silva (1865-1896), algunos críticos creen que compuso la obra "Nocturno", no para convocar a su hermana muerta, sino para describir con palabras el movimiento y el comportamiento de las luciérnagas

Antonio Machado (1875-1939), escribió un famoso poema titulada "Las moscas", en el que va describiendo alguno aspectos de su comportamiento y al mismo tiempo nos describe sus sensaciones y recuerdos.

Josep Graner i Puig-Oriol (1884-1970) conocido como el príncipe de los poetas catalanes. Una de sus obras se titula "El grill" (el grillo) en la que el insecto va enumerando sus cualidades y pide no ser matado ya que es un amigo.

Joan Savat Papasseit (1894-1924) máximo representante del futurismo en la literatura en lengua catalana. Tiene un caligrama titulado "Les formigues" (las hormigas) dedicado a su amigo Josep Llompart (Fig. 25).

Federico García Lorca (1898-1936) gran poeta y una de sus poesías se titula "Luna y panorama de los insectos", en las que se refiere a ellos de forma poética sin nombrarlos.

Pablo Neruda (1904-1973), poeta chileno considerado de los mejores del siglo XX en cualquier idioma según Gabriel García Márquez. Recibió el Premio Nobel de Literatura en 1971. Entre sus poesías destacaremos la titulada "El Insecto" una poesía erótica en la que el narrador se compara con un insecto que va recorriendo y describiendo el cuerpo de una mujer.

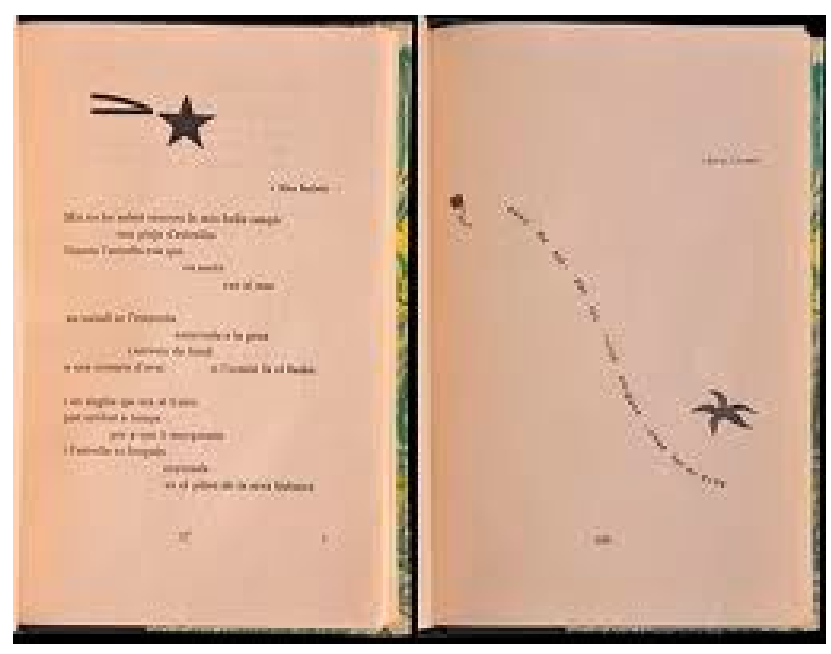

a

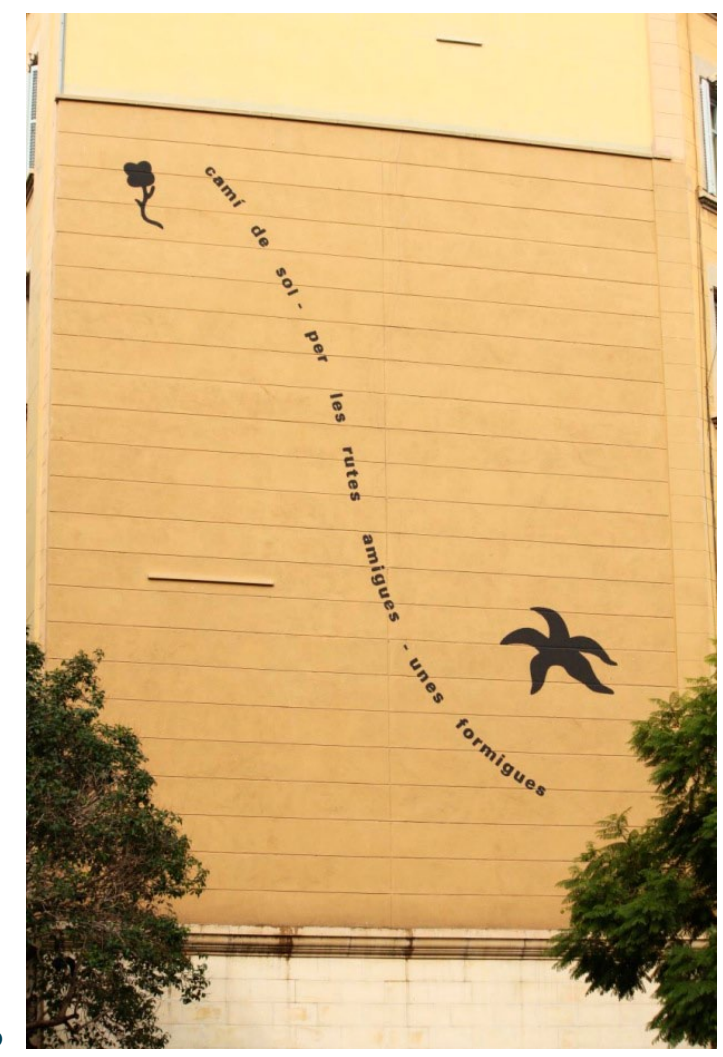

Figura 25 a y b: Un caligrama es una distribución de letras y palabras que pretenden la ilustración y/o la relación formal, con lo que dicen como texto. Es una conjunción de forma y contenido de índole plástico en la que la redundancia refuerza el significado y seduce formalmente. Figura 25 a : Abajo primera edición del caligrama las hormigas. Figura $25 \mathrm{~b}$ : abajo intervención artística en una pared medianera de Barcelona con el mismo referente. 
Para finalizar mencionaremos las obras literarias de algunos entomólogos. Entre ellos destacar el libro titulado "Cartas a Julie sobre la Entomología” (1830) escrito por el eminente entomólogo Étienne Mulsant (1797-1880) y "Recuerdos entomológicos" (18911879) obra de Jean-Henri Fabre (1823-1915) que han deleitado a numerosas generaciones de naturalistas (Moret, 1997). En poesía mencionaremos una obra L'Insectari (Vives, 2011) es un pequeño libro de poemas dedicado a los insectos, escrito por nuestro colega entomólogo Eduard Vives.

En este repaso sucinto por la literatura y la poesía, se pone de manifiesto que muchos de los más importantes escritores de la historia se han inspirado en los insectos para escribir algunos de sus libros y poemas. Mariposas, moscas, escarabajos, hormigas, saltamontes, libélulas, luciérnagas, pulgas y otros muchos insectos han sido los protagonistas de dichas obras. También al igual que en la música se han utilizado desde distintas perspectivas, metafóricas, simbólicas, anecdóticas etc...

\section{DANZA}

La danza representa en muchas culturas una forma de expresar emociones de interacción social, o un ejercicio en el marco espiritual o de representación. Sirve para expresar ideas, para contar una historia... La danza también puede ser contemplada como una forma de comunicación no verbal entre los humanos o en el mundo animal, como "la danza de las abejas" o "las danzas de apareamiento".

Hay muchos tipos de danzas y su definición depende de las normas sociales y culturales y de la sensibilidad artística, estética y moral.

La danza puede ser participativa, social o ser representada para una audiencia. También puede ser ceremonial, competitiva, erótica. Por otra parte la danza puede estar desprovista de significado por sí misma, como en un ballet o tener un vocabulario gestual o simbólico propio.

En la danza, quizás el arte en el que los insectos están menos representados, aunque en bailes ceremoniales de culturas antiguas de diferentes continentes, son imitados, por sus valores, ya sean positivos o negativos o bien se hacen para evitarlos a modo de conjuros.

En las fiestas populares, también están representados los insectos, como el "borinot de foc", típico del Vendrell (Tarragona). Este "abejorro" que emite fuego mientras baila y corre persiguiendo a los participantes, niños y adultos. Es una de las más recientes incorporaciones al "Bestiario imaginario catalán" y es transportado por jóvenes vestidos también como insectos (Figs. 26a y b).
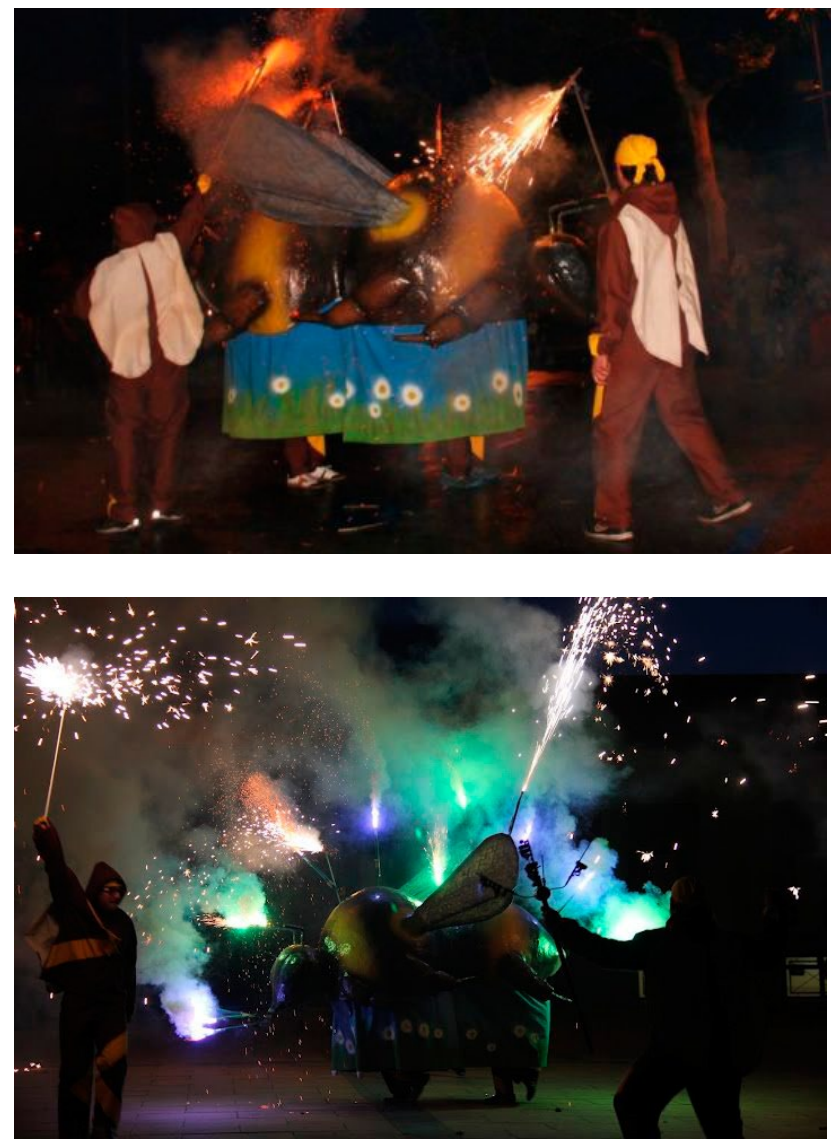

Figura 26 a y b: El "borinot de foc", se presentó en sociedad el 4 de junio de 2013 y desde entonces forma parte del Bestiari Imaginari de las fiestas de la población de Vendrell, Barcelona. Construido en fibra de vidrio pesa unos $80 \mathrm{~kg}$ y tiene 16 puntos de fuego.

En 2008, la compañía Nacional de Danza 2 representó en el Teatro de Madrid una obra titulada "Insected" con música de tribus del norte de Ghana. Destacar por último "El Cirque du Soleil", que suele presentar números en los que los artistas están caracterizados de formas sorprendentes y en múlti- 
ples ocasiones inspirados total o parcialmente en los insectos. Mención especial su espectáculo "OVO" (2010), en el que de forma directa representan de la vida de los insectos, en un continuo derroche de energía y movimiento (Fig. 27), con vestimentas que reproducen los diferentes insectos ideadas por Liz Vandal.

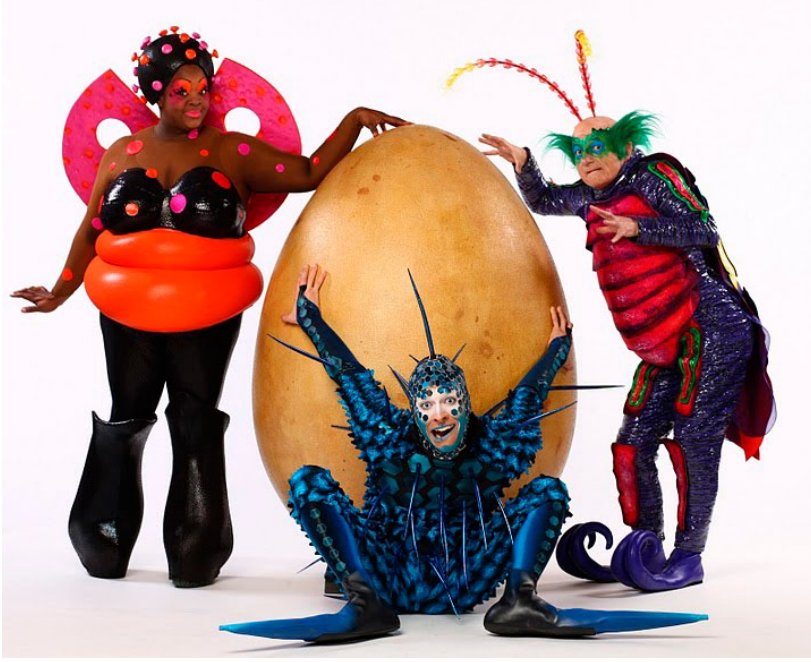

Figura 27: La diseñadora canadiense Liz Vandal recoge formas y colores de los insectos y los proyecta en las vestimentas de los diversos personajes y elabora unas piezas que además de espectaculares deben ser aptas, según los casos, para movimientos y acrobacias.

\section{CINE}

Desde la creación del cine, los insectos han aparecido en este medio virtual, ya sea como personajes populares o como monstruos que deben ser exterminados (Costa-Neto 2002). En general, los insectos no proyectan una imagen positiva, salvo en el caso de algunas películas de dibujos animados. En el cine, el término "insecto" no coincide necesariamente con el término científico de insecto. Así por ejemplo en el cine, cualquier organismo segmentado con patas articuladas es clasificado como insecto, sin importar el número de patas que tenga o si tiene antenas o no (Mariño \& Mendoza, 2006). Esto ha provocado que en muchos casos las arañas sean consideradas como insectos, aunque pertenecen a subtipos diferentes.

En el cine muchas veces los insectos tienen un tamańo gigantesco, que no es compatible con la fisiología de los mismos. Las feromonas en general son utilizadas con una cierta fidelidad. Los ciclos de vida a veces se ajustan poco a la realidad. En cuanto a la dinámica poblacional, en muchos casos difiere de la realidad. Un tema tratado en muchas películas es la introducción accidental o voluntaria de una especie, la manipulación del entorno ecológico, suele provocar desastres, lo cual es normalmente tan cierto en la vida tanto como en la ficción.

La lista de películas, ya sea de animación, de aventuras, de ciencia ficción, de terror entre otros estilos en la que intervienen los insectos como protagonistas o como personajes más o menos importantes es muy larga. Para comentar la forma en que se representan los insectos en el cine y televisión seguiremos la propuesta de Mariño \& Mendoza (2006): películas de animación, de "grandes bichos", películas de transformación/metamorfosis, películas de insectos sociales y documentales

En las películas de animación, los insectos muchas veces adquieren un aspecto antropomorfizado, hasta el punto de que caminan con dos patas y usan un par de apéndices como brazos. La cara es parecida a la de los humanos, con ojos, orejas, nariz y dientes, como en el caso de Pepito Grillo (Figs. $28 \mathrm{a}$ y b), personaje secundario que tenía el papel de la conciencia de Pinocho. La película de Pinocho se estrenó en 1940 y obtuvo dos premios Óscar, en las categorías de mejor banda sonora y mejor canción original. Bichos una aventura en miniatura (1998) fue nominada al Óscar por la mejor banda sonora original y está totalmente hecha por ordenador. En Bee Movy, la historia de una abeja (2007), el personaje principal (Barry) es una abeja recién graduada en la universidad que se encuentra algo decepcionada de su ocupación actual: hacer miel.

En las películas de "grandes bichos" los insectos son criaturas gigantescas, que atacan a los humanos y la condición de gigantes se debe a mutaciones, provocadas sobre todo por radiaciones o por manipulación genética. Este tipo de películas suele ser de ciencia ficción y terror. La primera película de estas características fue "Them" (Figs. 29a y b) estrenada en 1954 es una película de ciencia ficción que narra 


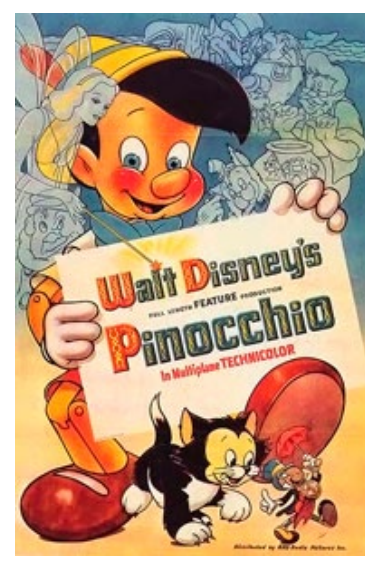

a

b

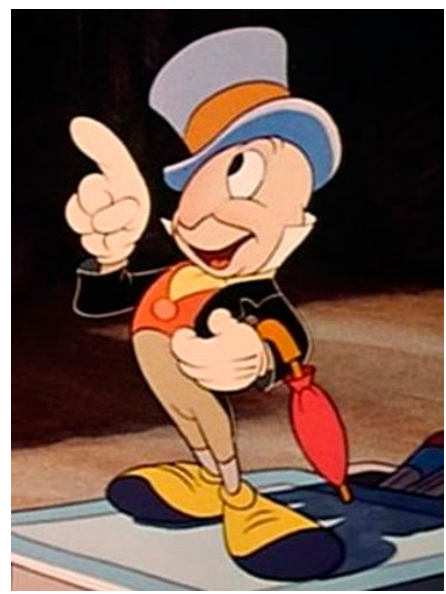

Figura 28 a y b : Cartel del estreno de la película Pinocchio, 1940. Aunque Pepito Grillo (b) muere accidentalmente por acción del propio Pinocho (a) es la versión original, Disney no le reserva este destino y sí el de ser una conciencia permanente, rigurosa y amable.

el enfrentamiento de la humanidad contra una raza mutante de hormigas gigantes. Esta película también es conocida con los títulos de "La humanidad en peligro" o "El mundo en peligro". Otros ejemplos son "El principio del fin" (2008), el "El imperio de las hormigas" (1977) película de ciencia ficción y "El monstruo alado" (1957) película de terror y ciencia ficción.

En las películas de Transformación /Metamorfosis, lo más común es la transformación de insecto a humano o de humano a insectos, o bien la transformación debido a manipulación genética, dando lugar a films de ciencia ficción o terror. Películas de estas características son "La mosca" (1980) "El nido" (1987) y "Mimic" (1997) (Berembaun, 2000).

Las películas de insectos sociales, están protagonizadas por himenópteros, abejas, avispas y hormigas fundamentalmente. En la mayoría de los casos resultan muy perjudiciales, debido a procesos de manipulación genética, cambio en las condiciones ambientales etc.. Las películas en las que los protagonistas son los insectos sociales pueden ser de
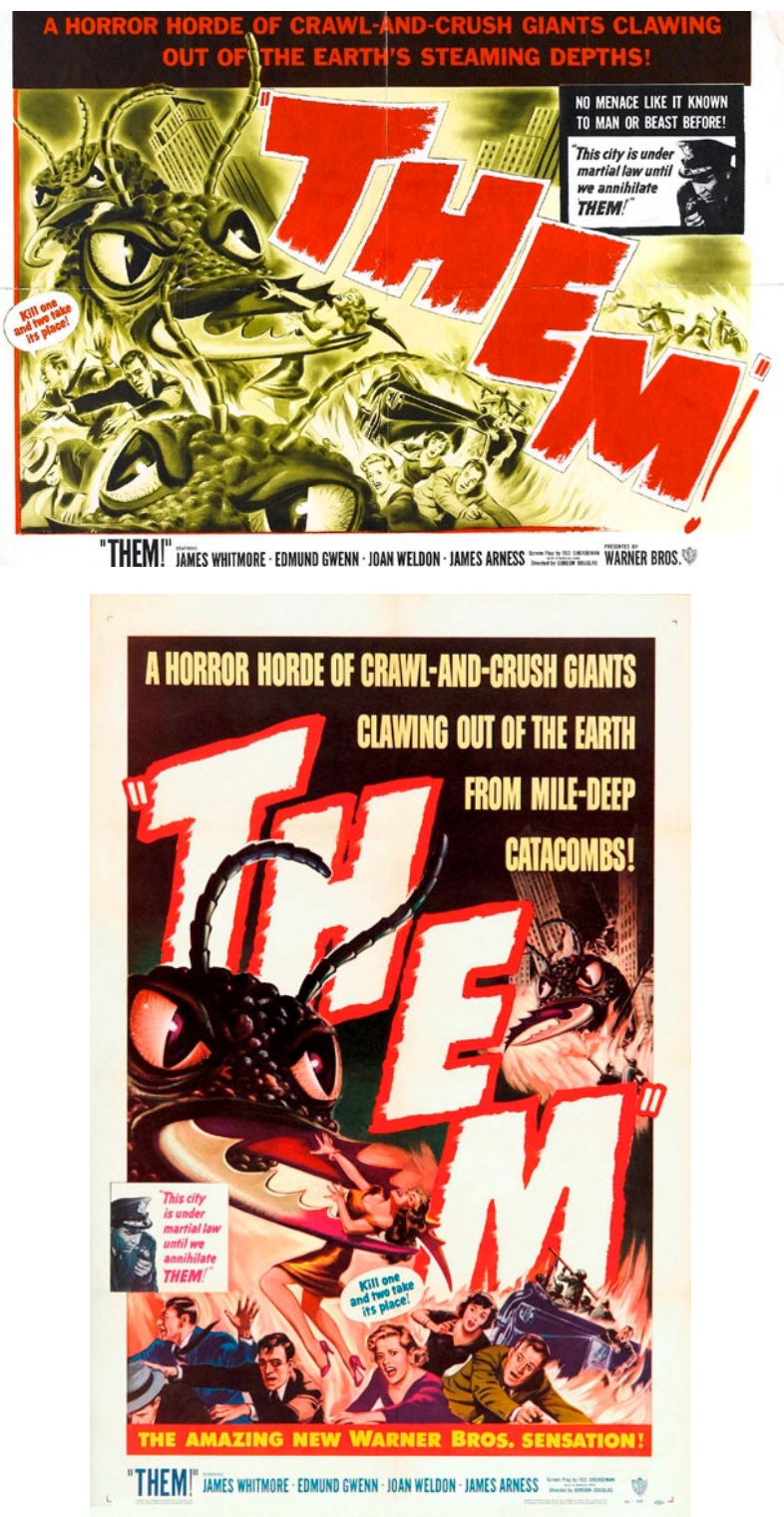

Figura 29 a y b : Dos versiones del cartel original de "Them", 1954.

aventuras, de ciencia ficción, de terror, etc.. Una de las películas más famosas de aventuras es "Cuando ruge la marabunta" (1954) (Fig. 30). "El imperio de las hormigas" (1977) y Atrapados en el enjambre (2005) son películas de terror. "Abejas asesinas" (2002), "Avispas asesinas” (TV 2007, 2012), “Hormigas asesinas" (TV 2007). En ellas los protagonistas son insectos con mutaciones genéticas, en la mayoría de los casos provocadas por investigadores. Otra película de terror que se ha convertido en inicio de exitosa sagas y genuino culto cinéfilo es "Alien, el octavo pasajero" dirigida por Ridley Scott (1979),

Un último apunte para situar a los insectos como 


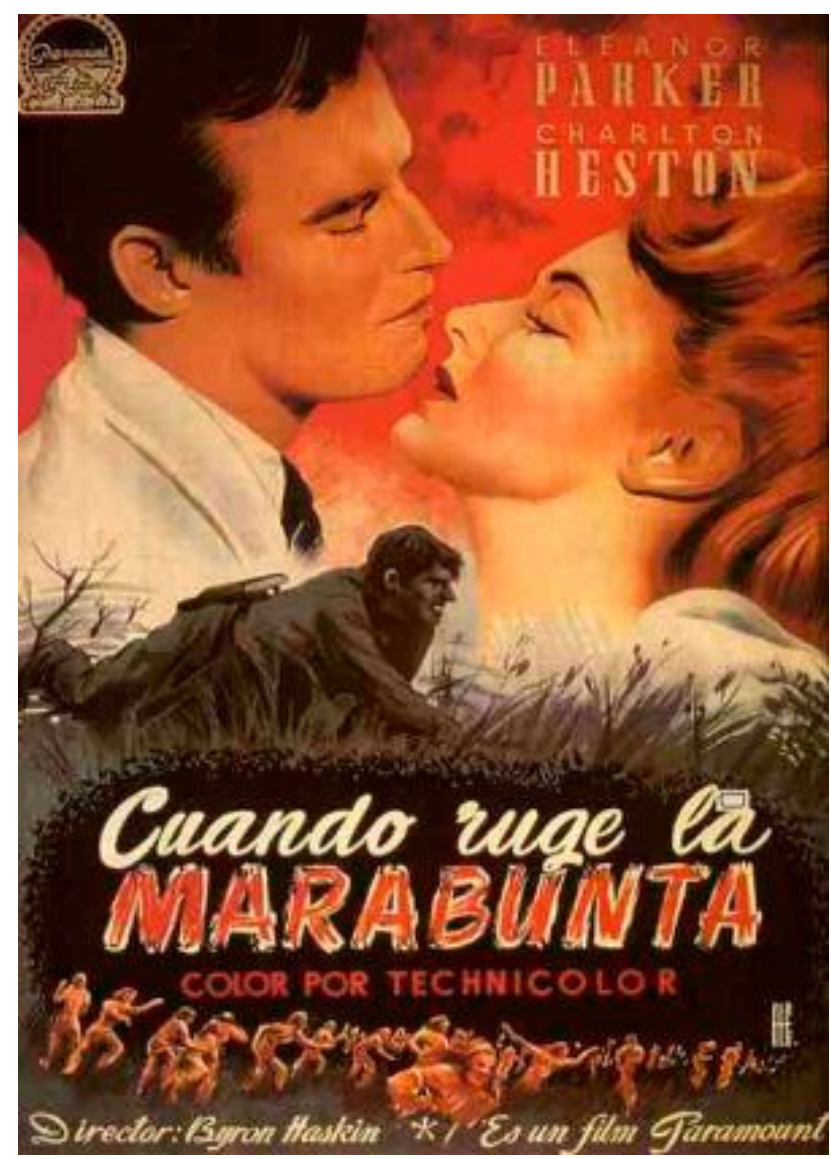

Figura 30: Cartel original del estreno en España, de la película "Cuando ruge la marabunta" (1954).

elementos clave en la trama de algunas películas, es el caso de "El silencio de los corderos", (1991), (Fig.31), ganadora de cinco Òcars y en la que una crisálida identificada por unos entomólogos como de Acherontia styx, mariposa "cabeza de muerte", es la pieza que permite situar el lugar en que se retiene a la joven secuestrada y tras eso la captura del criminal.

Como ya hemos indicado la lista de películas con insectos es muy larga y hay películas muy relevantes del género. Entre los grupos más utilizados están en primer lugar los himenópteros (abejas, avispas y hormigas), las cucarachas, las polillas, las moscas y mosquitos y los saltamontes, aunque el grupo más terrorífico son las "arańas", considerados como tipo "insectos" en el cine (Mariño \& Mendoza, 2006).

Cada vez son más numerosos los documentales sobre la vida, en sus diversos aspectos de los insec-

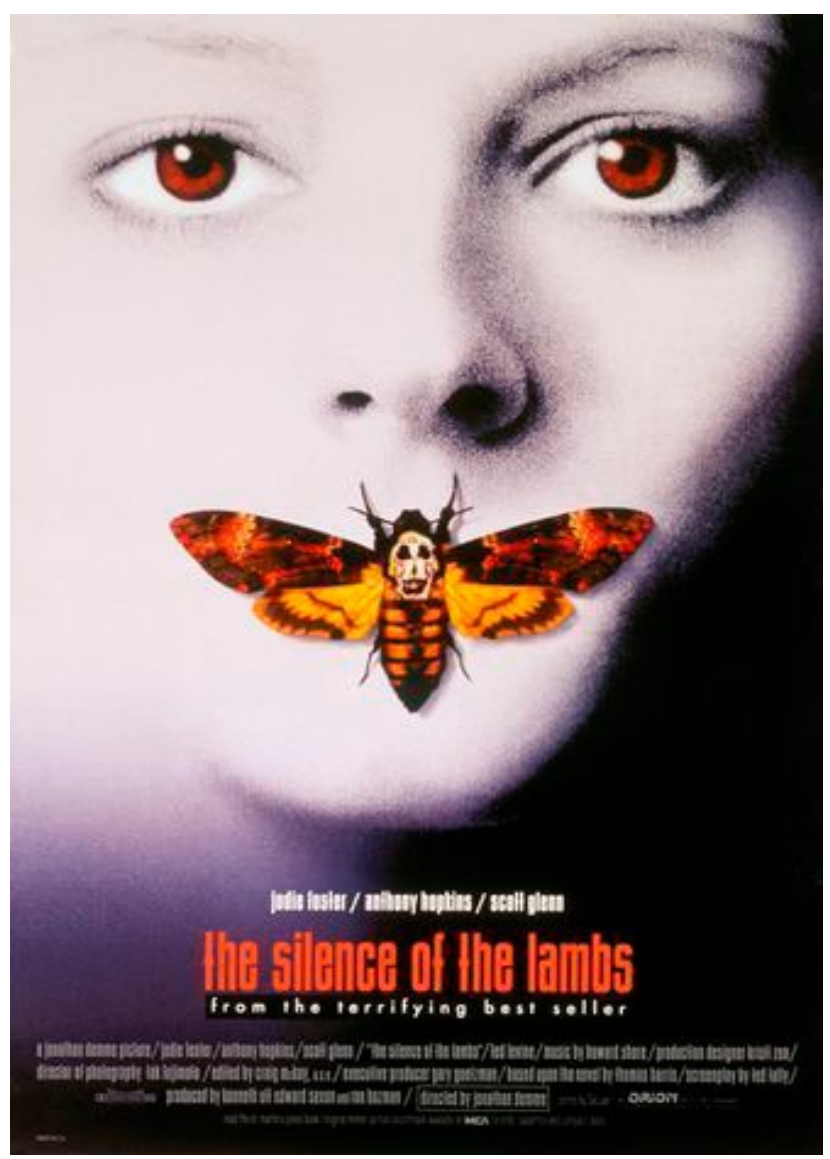

Figura 31: Cartel original de "El silencio de los corderos", 1991. El protagonismo entomológico en el desentramado del nudo argumental es todo un referente de la interconexión multidisciplinar.

tos. Estos documentales suelen ser muy didácticos y su incremento ha sido posible al desarrollo de la fotografía y de la tecnología electrónica. El primer documental sobre insectos fue realizado por el británico F. Percy Smith (1880-1945) en 1912 y versaba sobre la mosca doméstica, por lo que es considerado como el pionero en este clase de cine. (http://en.wikipedia.org/wiki/F._Percy_Smith).

Como conclusión de este apartado se podría decir que en el cine el concepto de insectos es más amplio, que el científico. Que en general se presentan como organismos perjudiciales, ya que suelen atacar al hombre que es bueno que ha de luchar contra estas criaturas maléficas, que en ocasiones han sido producidas por el mismo hombre, fruto de la manipulación genética. En cuanto a las películas de animación, los insectos suelen estar humanizados y algunos resultan hasta simpáticos. 


\section{CONCLUSIONES}

Existe una amplia diversidad de enfoques y de matices en la manifestación de los insectos en las artes mayores, que dependen de la idiosincrasia propia de cada arte, de sus funciones culturales y de los momentos y estilos en las que se desarrollan.

La presencia de los insectos se puede organizar por su significado, es decir por su aporte como valor de fuente de inspiración que puede ser de forma directa o de forma indirecta.

Otra manera de contemplar sus influencias en las artes es recabar en el estilo del vínculo que proponen: morfológico, filosófico, superficial, estructural, anecdótico. Morfología, comportamiento, organización social, hábitats..., son recursos que los humanos aprovechamos de su observación.

La relación entre insectos y arte es tan polifacética como nos la podamos imaginar, del más riguroso realismo a la pura invención.

La biodiversidad de los insectos en el arte, es muy elevada y su manifestación ha podido influir en la conservación de las especies y/o grupos de insectos.

Como ya indicamos creemos que no se debe separar la biodiversidad cultural de la biodiversidad biológica.

$\mathrm{Al}$ margen del hecho de encontrarse en un lugar $\mathrm{u}$ otro el contexto socio cultural es un factor relevante para su conservación, de tal forma que si estamos ante la "adoración" podemos constatar la atención al grupo y a las especies, y en consecuencia se favorece su conservación. Si nos situamos ante el miedo, desprecio o asco, la consecuencia, en muchos casos, es situarlos ante el exterminio casi seguro y rápido.

\section{REFERENCIAS}

AA. VV. 2000. Arte e Historia Roma y el Vaticano. Ed. Bonechi. Florencia..

Batta, A. \& Neef, S. 2000. Ópera. Compositores. Obras. Barcelona, 2000.
Bellés, X. 2000. Precursores de la Entomología. Ulisse Aldrovandi (1522-1605). Aracnet, 6. Boletín Sociedad Entomológica Aragonesa (S.E.A.), 27: 6

Calle, E. 2009. Los insectos y su impacto en la cultura. UN Periódico impreso $n^{\circ} 126$. www.unperiodico.unal.edu.co/

Coelho, J. 2000. Insects in Rock \& Roll Music. American Entomologist, 46(3): 186-195

Costa-Neto, E.M. 2002. Manual de Etnoentomologia: Manuales \& Tesis SEA. Sociedad Entomológica Aragonesa. Zaragoza

Costa-Neto, E.M.; Santos-Fita, D.\& Serrano González. 2012. La investigación etnoentomológica y la conservación de la biodiversidad. Boletín Sociedad Entomológica Aragonesa (S.E.A.), 51: 367-369)

Ferrer, J. 2009. Entomología fantástica: Las moscas de las madonas de Carlo Crivelli. Boletín Sociedad Entomológica Aragonesa (S.E.A.), 44: 599-602.

Gurrea, M.P. \& Martín Cano, J. 2007. Los insectos en las Pinturas del Museo del Prado de Madrid (España); p:103136. En: Entomología cultural: una visión iberoamericana. Navarrete-Heredia, J.L.; Quiroa-Rocha, G.A. \& FierrosLópez, H-E. Eds. Universidad de Guadalajara. México.

Hogue, CH. 1987. Annual Review of Entomology, vol. 32.

LLorens Duran, J.I. 2008. Zoomorfismo y bioárquitectura. Entre la analogía formal y la aplicación de los principios de la naturaleza. http://upcommons.upc.edu/e-prints/ bitstream/2117/2156/1/V\%20-\%20Llorens\%20 Duran,\%20J.I.\%20de.pdf

Mariño Pérez, R. \& Mendoza Almeralla, C. 2006. Los insectos en el cine. Un estudio preliminar. Boletín Sociedad Entomológica Aragonesa (S.E.A.), 38: 415-421.

Montserrat, V. 2009a. Los artrópodos en la obra de Hieonymus Van Aken (El Bosco). Boletín Sociedad Entomológica Aragonesa (S.E.A.), 45: 589-615.

Montserrat, V. 2009b. Los artrópodos en la vida y en la obra de Vicent Van Gogh. Boletín Sociedad Entomológica Aragonesa (S.E.A.), 44: 629-641.

Moret, P. 1997. Los insectos en la literatura moderna. Boletín Sociedad Entomológica Aragonesa (S.E.A.), 20: 443-450

Vives, E. 2011. L'Insectari. Poemes d'Eduard Vives. Margalef de Montsat Terrassa. 55 p. 
Sachs, 1997. A cooperaçao Sul-Sul o desenvolvimento sustentável nos trópicos úmidos. En Aragón, L.E. \& M. Clüsener-Godt (org.). Reservas da biosfera e reservas extrativistas: conservaçao da biodiversidade e ecodesenvolvimento. Belém: Associaçao das Universidades Amazonicas/UNESCO: 1-8. http://entomologia.rediris.es/aracnet/6/precursores2/

http://www.revistadelauniversidad.unam.mx/4207/pdfs/36-39.pdf

http://es.wikipedia.org/wiki/Bellas_artes

http://en.wikipedia.org/wiki/F__Percy_Smith

http://en.wikipedia.org/wiki/Ricciotto_Canudo 